NBER WORKING PAPER SERIES

\title{
SELF-FULFILLING DEBT CRISES: CAN MONETARY POLICY REALLY HELP?
}

\author{
Philippe Bacchetta \\ Elena Perazzi \\ Eric van Wincoop \\ Working Paper 21158 \\ http://www.nber.org/papers/w21158
NATIONAL BUREAU OF ECONOMIC RESEARCH
1050 Massachusetts Avenue
Cambridge, MA 02138

May 2015

We would like to thank Luca Dedola, Kenza Benhima, Celine Poilly, and seminar participants at the University of Lausanne, ETH Zurich, and participants at the ECB conference "Nonlinearities in macroeconomics and finance in light off crises" and the UVA-Richmond Fed research conference for helpful comments and suggestions. We gratefully acknowledge financial support from the Bankard Fund for Political Economy and the ERC Advanced Grant \#269573. The views expressed herein are those of the authors and do not necessarily reflect the views of the National Bureau of Economic Research.

NBER working papers are circulated for discussion and comment purposes. They have not been peerreviewed or been subject to the review by the NBER Board of Directors that accompanies official NBER publications.

(C) 2015 by Philippe Bacchetta, Elena Perazzi, and Eric van Wincoop. All rights reserved. Short sections of text, not to exceed two paragraphs, may be quoted without explicit permission provided that full credit, including $\odot$ notice, is given to the source. 
Self-Fulfilling Debt Crises: Can Monetary Policy Really Help?

Philippe Bacchetta, Elena Perazzi, and Eric van Wincoop

NBER Working Paper No. 21158

May 2015

JEL No. E52,E60,E63

\begin{abstract}
$\underline{\text { ABSTRACT }}$
This paper examines quantitatively the potential for monetary policy to avoid self-fulfilling sovereign debt crises. We combine a version of the slow-moving debt crisis model proposed by Lorenzoni and Werning (2014) with a standard New Keynesian model. We consider both conventional and unconventional monetary policy. Under conventional policy the central bank can preclude a debt crisis through inflation, lowering the real interest rate and raising output. These reduce the real value of the outstanding debt and the cost of new borrowing, and increase tax revenues and seigniorage. Unconventional policies take the form of liquidity support or debt buyback policies that raise the monetary base beyond the satiation level. We find that generally the central bank cannot credibly avoid a self-fulfilling debt crisis. Conventional policies needed to avert a crisis require excessive inflation for a sustained period of time. Unconventional monetary policy can only be effective when the economy is at a structural ZLB for a sustained length of time.
\end{abstract}

Philippe Bacchetta

Faculty of Business and Economics

University of Lausanne

Intranef 523

CH-1015 Lausanne

Switzerland

philippe.bacchetta@unil.ch

Elena Perazzi

Faculty of Business and Economics

University of Lausanne

Intranef 506

CH-1015 Lausanne

Switzerland

Elena.Perazzi.2@unil.ch
Eric van Wincoop

Department of Economics

University of Virginia

P.O. Box 400182

Charlottesville, VA 22904-4182

and NBER

vanwincoop@virginia.edu 


\section{Introduction}

A popular explanation for the sovereign debt crisis that has impacted European periphery countries since 2010 is self-fulfilling sentiments. If market participants believe that sovereign default of a country is more likely, they demand higher spreads, which over time raises the debt level and therefore indeed makes eventual default more likely. ${ }^{1}$ This view of self-fulfilling beliefs is consistent with the evidence that the surge in sovereign bond spreads in Europe during 2010-2011 was disconnected from debt ratios and other macroeconomic fundamentals (e.g., de Grauwe and Ji, 2013). However, countries with comparable debt and deficits outside the Eurozone (e.g., the US, Japan or the UK) were not impacted. This difference in experience has often been attributed to the fact that the highly indebted non-Eurozone countries have their own currency. ${ }^{2}$ The central bank has additional tools to support the fiscal authority, either in the form of standard inflation policy or by providing liquidity, which can avoid self-fulfilling debt crises. In fact, the decline in European spreads since mid 2012 is widely attributed to a change in ECB policy towards explicit backing of periphery government debt.

The question that we address in this paper is whether central banks can credibly avert self-fulfilling debt crises. This is a quantitative question that requires a reasonably realistic model. Existing models of self-fulfilling sovereign debt crises either take the form of liquidity or rollover crises, such as Cole and Kehoe (2000), or models in the spirit of Calvo (1988), where default becomes self-fulfilling by raising the spread on sovereign debt. ${ }^{3}$ In this paper we are interested in the second type of self-fulfilling crises, which fits more closely with the experience in

\footnotetext{
${ }^{1}$ This view was held by the ECB President Draghi himself: “... the assessment of the Governing Council is that we are in a situation now where you have large parts of the euro area in what we call a "bad equilibrium", namely an equilibrium where you may have self-fulfilling expectations that feed upon themselves and generate very adverse scenarios." (press conference, September 6, 2012). In the academic literature, versions of this argument can be found, among others, in Aguiar et al. (2013), Camous and Cooper (2014), Cohen and Villemot (2015), Conesa and Kehoe (2015), Corsetti and Dedola (2014), de Grauwe (2011), de Grauwe and Ji (2013), Gros (2012), Jeanne (2012), Jeanne and Wang (2013), Krugman (2013), Lorenzoni and Werning (2014), Navarro et al. (2014), and Miller and Zhang (2012).

${ }^{2}$ See for example de Grauwe (2011), de Grauwe and Jin (2013), Jeanne (2012) and Krugman (2013).

${ }^{3}$ Navarro et al. (2014) show that this mechanism can also arise in sovereign debt models in the line of Eaton and Gersovitz (1988).
} 
Europe. However, while the contribution by Calvo was important in highlighting the mechanism, it uses a two-period setup that quantitatively is of limited interest.

We therefore analyze the role that the central bank can play in the context of a framework developed by Lorenzoni and Werning (2014), which extends the mechanism of Calvo (1988) to a more dynamic setting. The model exhibits "slow moving" debt crises. The anticipation of a possible future default on long term bonds leads interest rates and debt to gradually rise over time, justifying the belief of ultimate default. This framework has two advantages. First, while the mechanism is in the spirit of Calvo (1988), the presence of long-term debt and more realistic dynamics provides a better framework for quantitatively evaluating the role of monetary policy. The slow-moving nature of the crisis also gives the central bank more time to act to support the fiscal authority. Second, the model connects closely to the recent experience in Europe, where sovereign default spreads rose over several years without setting off immediate default events.

While the LW model is real and does not have a monetary authority, we analyze the role of monetary policy by incorporating the LW framework into a standard New Keynesian model. We follow the literature and consider a specification that yields empirically consistent responses of output and inflation to monetary shocks. We then first analyze the role of conventional monetary policy. Expansionary policy that lowers interest rates, raises inflation and raises output slows down government debt accumulation in four ways. First, lower real interest rates reduce the real cost of new borrowing. Second, inflation erodes the value of outstanding debt. Third, higher output raises government tax revenue. Finally, an increase in the money supply generates seigniorage revenue.

Most of the paper considers the case, also analyzed in LW, where the decision to default or not takes place at a known future date $T$. At that time uncertainty about future fiscal surpluses is resolved. At an initial date 0 a self-fulfilling expectation shock can lead to beliefs of default at time $T$. Investors then demand a higher yield on new debt, which leads to a more rapid accumulation of debt between the initial period 0 and the default period $T$. If debt is large enough, default may occur due to insolvency. There is a range of initial debt levels at time 0 for which self-fulfilling crises may occur. Monetary policy can be used to relax the solvency constraint both ex ante, before $T$, and ex post, after $T$. We also consider an extension in which there is uncertainty about $T$.

Sufficiently aggressive monetary policy can in principle preclude a self-fulfilling 
debt crisis. However, the policy needs to be credible and therefore not too costly, especially in terms of inflation. Assuming reasonable parameters of the model and the debt maturity structure, we find that avoiding a crisis equilibrium is typically very costly. For example, with an initial debt level in the middle of the multiplicity range ( $112 \%$ of GDP), optimal policy that avoids a self-fulfilling crisis implies that prices ultimately increase by a factor of 5 and the peak annual inflation rate is $24 \%$. Avoiding self-fulfilling equilibria requires very steep inflation rates for a sustained period of time, the cost of which is likely to be much larger than that of allowing the government to default. We find that this result is robust to significant changes in the assumed parameters of both the LW and NK components of the model.

We also consider unconventional monetary policy, where the monetary base is expanded beyond the satiation level of money demand. We consider both a liquidity support policy, whereby the consolidated government issues monetary liabilities instead of new debt, and a debt buyback policy, where existing government debt is replaced with monetary liabilities. An important advantage of such policies is that, in contrast to government debt, there is no payment of default premia on monetary liabilities. Nonetheless we find that such policies can only be effective if the economy is at a structural zero lower bound (ZLB), where the natural real interest rate is zero or negative, for a sustained period of time.

We consider the case where a central bank aims to avoid default of the central government. As we briefly discuss toward the end of the paper, our main result that a central bank can generally not credibly avoid a self-fulfilling debt crisis does not apply to the situation in Europe in the summer of 2012, when the ECB aimed to avoid default in a limited periphery of the currency union. The ECB could for example sell German bonds and buy Spanish bonds at low interest rates, without any monetary expansion. Just the threat alone of such a policy is sufficient to avoid the default equilibrium.

The impact of monetary policy in a self-fulfilling debt crisis environment was first analyzed by Calvo (1988), who examined the trade-off between outright default and debt deflation. Corsetti and Dedola (2014) extend the Calvo model to allow for both fundamental and self-fulfilling default. They show that with optimal monetary policy debt crises can still happen, but for larger levels of debt. They also show that a crisis can be avoided if government debt is replaced by central bank debt that is convertible into cash. Reis (2013) and Jeanne (2012) both develop stylized two-period models with multiple equilibria to illustrate ways in 
which the central bank can act to avoid the bad equilibrium.

Some papers consider more dynamic models. Camous and Cooper (2014) use a dynamic overlapping-generation model with strategic default. They show that the central bank can avoid self-fulfilling default if they commit to a policy where inflation depends on the state (productivity, interest rate, sunspot). Aguiar et al. (2013) consider a dynamic model to analyze the vulnerability to self-fulfilling rollover crises, depending on the aversion of the central bank to inflation. Although a rollover crisis occurs suddenly, it is assumed that there is a grace period to repay the debt, allowing the central bank time to reduce the real value of the debt through inflation. They find that only for intermediate levels of the cost of inflation do debt crises occur under a narrower range of debt values.

All these papers derive analytical conditions under which central bank policy would avoid a self-fulfilling debt crisis. This delivers interesting insights, but does not answer the more quantitative question whether realistically the central bank can be expected to adopt a policy that prevents a self-fulfilling crisis. In order to do so we relax the assumptions of one-period bonds, flexible prices, and instantaneous crises that are adopted in the literature above for tractability reasons. ${ }^{4}$

The rest of the paper is organized as follows. Section 2 presents the slow-moving debt crisis model based on LW. It starts with a real version of the model and then presents its extension to a monetary environment. Subsequently, it analyzes the various channels of monetary policy in this framework. Section 3 describes the New Keynesian part of the model and its calibration. Section 4 analyzes the quantitative impact of conventional monetary policy and Section 5 considers unconventional monetary policy. After a discussion of related questions in Section 6, Section 7 concludes. Some of the technical details are left to the Appendix, while additional algebraic details and results can be found in a separate Technical Appendix.

\footnotetext{
${ }^{4}$ There are recent models that examine the impact of monetary policy in the presence of longterm government bonds. Leeper and Zhou (2013) analyze optimal monetary (and fiscal) policy with flexible prices, while Bhattarai et al. (2013) consider a New Keynesian environment at ZLB. These papers, however, do not allow for the possibility of sovereign default. Sheedy (2014) and Gomes et al. (2014) examine monetary policy with long-term private sector bonds.
} 


\section{A Model of Slow-Moving Self-Fulfilling Debt Crisis}

In this section we present a dynamic sovereign debt crisis model based on LW. We first describe the basic structure of the model in a real environment. We then extend the model to a monetary environment and discuss the impact of monetary policy on the existence of self-fulfilling debt crises. We focus on the dynamics of asset prices and debt for given interest rates and goods prices. The latter will be determined in a New Keynesian model that we describe in Section 3.

\subsection{A Real Model}

We consider a simplified version of the LW model. As in the applications considered by LW, there is a key date $T$ at which uncertainty about future primary surpluses is resolved and the government makes a decision to default or not. ${ }^{5}$ Default occurs at time $T$ if the present value of future primary surpluses is insufficient to repay the debt. We assume that default does not happen prior to date $T$ as there is always a possibility of large primarily surpluses from $T$ onward. In one version of their model LW assume that $T$ is known to all agents, while in another they assume that it is unknown and arrives each period with a certain probability. We mostly adopt the former assumption. In section 4.3 we briefly discuss an extension where $T$ is uncertain.

The only simplification we adopt relative to LW concerns the process of the primary surplus. For now we assume that the primary surplus $s_{t}$ is constant at $\bar{s}$ between periods 0 and $T-1$. Below we extend this by allowing for a procyclical primary surplus. ${ }^{6}$ A second assumption concerns the primary surplus value starting at date $T$. Let $\tilde{s}$ denote the maximum potential primary surplus that the government is able to achieve, which becomes known at time $T$ and is constant from thereon. LW assume that it is drawn from a log normal distribution. Instead we assume that it is drawn from a binary distribution, which simplifies the algebra

\footnotetext{
${ }^{5}$ One can for example think of countries that have been hit by a shock that adversely affected their primary surpluses, which is followed by a period of uncertainty about whether and how much the government is able to restore primary surpluses through higher taxation or reduced spending.

${ }^{6} \mathrm{LW}$ assume a fiscal rule whereby the surplus is a function of debt.
} 
and the presentation. It can take on only two values: $s_{\text {low }}$ with probability $\psi$ and $s_{\text {high }}$ with probability $1-\psi$. When the present discounted value of $\tilde{s}$ is at least as large as what the government owes on debt, there is no default at time $T$ and the actual surplus is just sufficient to satisfy the budget constraint (generally below $\tilde{s})$. We assume that $s_{\text {high }}$ is big enough such that this is always the case when $\tilde{s}=s_{\text {high }} \cdot{ }^{7}$ When $\tilde{s}=s_{\text {low }}$ and its present value is insufficient to repay the debt, the government defaults.

A key feature of the model is the presence of long-term debt. As usual in the literature, assume that bonds pay coupons (measured in goods) that depreciate at a rate of $1-\delta$ over time: $\kappa,(1-\delta) \kappa,(1-\delta)^{2} \kappa$, and so on. ${ }^{8}$ A smaller $\delta$ therefore implies a longer maturity of debt. This facilitates aggregation as a bond issued at $t-s$ corresponds to $(1-\delta)^{s}$ bonds issued at time $t$. We can then define all outstanding bonds in terms of the equivalent of newly issued bonds. We define $b_{t}$ as debt measured in terms of the equivalent of newly issued bonds at $t-1$ on which the first coupon is due at time $t$. As in LW, we take $\delta$ as given. It is associated with tradeoffs that are not explicitly modeled, and we do not allow the government to change the maturity to avoid default.

Let $Q_{t}$ be the price of a government bond. At time $t$ the value of government debt is $Q_{t} b_{t+1}$. In the absence of default the return on the government bond from $t$ to $t+1$ is

$$
R_{t}^{g}=\frac{(1-\delta) Q_{t+1}+\kappa}{Q_{t}}
$$

If there is default at time $T$, bond holders are able to recover a proportion $\zeta<1$ of the present discounted value $s^{p d v}$ of the primary surpluses $s_{l o w} \cdot{ }^{9}$ In that case the return on the government bond is

$$
R_{T-1}^{g}=\frac{\zeta s^{p d v}}{Q_{T-1} b_{T}}
$$

Government debt evolves according to

$$
Q_{t} b_{t+1}=R_{t-1}^{g} Q_{t-1} b_{t}-s_{t}
$$

\footnotetext{
${ }^{7}$ See Technical Appendix for details.

${ }^{8}$ See for example Hatchondo and Martinez (2009).

${ }^{9}$ One can think of $\zeta$ as the outcome of a bargaining process between the government (representing taxpayers) and bondholders. Since governments rarely default on all their debt, we assume $\zeta>0$.
} 
In the absence of default this may also be written as $Q_{t} b_{t+1}=\left((1-\delta) Q_{t}+\kappa\right) b_{t}-s_{t}$. The initial stock of debt $b_{0}$ is given.

We assume that investors also have access to a short-term bond with a gross real interest rate $R_{t}$. The only shocks in the model occur at time 0 (self-fulfilling shock to expectations) and time $T$ (value of $\tilde{s}$ ). In other periods the following risk-free arbitrage condition holds (for $t \geq 0$ and $t \neq T-1$ ):

$$
R_{t}=\frac{(1-\delta) Q_{t+1}+\kappa}{Q_{t}}
$$

For now we assume, as in LW, a constant interest rate, $R_{t}=R$. In that case $s^{p d v}=R s_{\text {low }} /(R-1)$ is the present discounted value of $s_{\text {low }}$. There is no default at time $T$ if $s^{p d v}$ covers current and future debt service at $T$, which is $\left((1-\delta) Q_{T}+\kappa\right) b_{T}$. Since there is no default after time $T, Q_{T}$ is the risk-free price, equal to the present discounted value of future coupons. For convenience it is assumed that $\kappa=R-1+\delta$, so that (4) implies that $Q_{T}=1$. This means that there is no default as long as $s^{p d v} \geq R b_{T}$, or if

$$
b_{T} \leq \frac{1}{R-1} s_{\text {low }} \equiv \tilde{b}
$$

When $b_{T}>\tilde{b}$, the government partially defaults on debt, with investors seizing a fraction $\zeta$ of the present value $s^{p d v}$.

This framework may lead to multiple equilibria and to a slow-moving debt crisis, as described in LW. The existence of multiple equilibria can be seen graphically from the intersection of two schedules, as illustrated in Figure 1. The first schedule, labeled "pricing schedule", is a consistency relationship between price and outstanding debt at $T-1$, in view of the default decision that may be taken at $T$. This is given by:

$$
\begin{aligned}
Q_{T-1} & =1 & & \text { if } b_{T} \leq \tilde{b} \\
& =\psi \frac{\zeta s^{p d v}}{R b_{T}}+(1-\psi) & & \text { if } b_{T}>\tilde{b}
\end{aligned}
$$

When $b_{T} \leq \tilde{b}$, the arbitrage condition (4) also applies to $t=T-1$, implying $Q_{T-1}=1$. When $b_{T}$ is just above $\tilde{b}$, there is a discrete drop of the price because only a fraction $\zeta$ of primary surpluses can be recovered by bond holders in case of default. For larger values of debt, $Q_{T-1}$ will be even lower as the primary surpluses have to be shared among more bonds. 
The second schedule is the "debt accumulation schedule", which expresses the amount of debt that accumulates through time $T-1$ as a function of prices between 0 and $T-1$. Since every price $Q_{t}$ between 0 and $T-1$ can be expressed as a function of $Q_{T-1}$, by integrating (4) backwards from $T-1$ to 0 we obtain

$$
Q_{t}-1=\left(\frac{1-\delta}{R}\right)^{T-1-t}\left(Q_{T-1}-1\right)
$$

Substituting in (3) and integrating the government budget constraint forward from 0 to $T-1$, we get (see Appendix A):

$$
b_{T}=(1-\delta)^{T} b_{0}+\frac{\chi^{\kappa} \kappa b_{0}-\chi^{s} \bar{s}}{Q_{T-1}}
$$

where

$$
\begin{aligned}
& \chi^{\kappa}=R^{T-1}+(1-\delta) R^{T-2}+(1-\delta)^{2} R^{T-3}+\ldots+(1-\delta)^{T-1} \\
& \chi^{s}=1+R+R^{2}+\ldots+R^{T-1}
\end{aligned}
$$

The numerator $\chi^{\kappa} \kappa b_{0}-\chi^{s} \bar{s}$ in (9) corresponds to the accumulated new borrowing between 0 and $T$. We assume that it is positive, which happens when the primary surplus is insufficient to pay the coupons on the initial debt. A sufficient, but not necessary, condition is that the primary surplus itself is negative during this time. The debt accumulation schedule then gives a negative relationship between and $b_{T}$ and $Q_{T-1}$. When $Q_{T-1}$ is lower, asset prices from 0 to $T-2$ are also lower. This implies a higher yield on newly issued debt, reflecting a premium for possible default at time $T$. These default premia lead to a more rapid accumulation of debt and therefore a higher $b_{T}$ at $T-1$.

Figure 1 shows these two schedules and illustrates the multiplicity of equilibria. There are two stable equilibria, represented by points $\mathrm{A}$ and $\mathrm{B}$. At point $\mathrm{A}, Q_{T-1}=$ 1. The bond price is then equal to 1 at all times. This is the "good" equilibrium in which there is no default. At point B, $Q_{T-1}<1$. This is the "bad" equilibrium. Asset prices starting at time 0 are less than 1 in anticipation of possible default at time $T$. Intuitively, when agents believe that default is likely, they demand default premia (implying lower asset prices), leading to a more rapid accumulation of debt, which in a self-fulfilling way indeed makes default more likely.

In the bad equilibrium there is a slow-moving debt crisis. As can be seen from (8), using $Q_{T-1}<1$, the asset price instantaneously drops at time 0 and 
then continues to drop all the way to $T-1$. Correspondingly, default premia gradually rise over time. Such a slow-moving crisis occurs only for intermediate levels of debt. When $b_{0}$ is sufficiently low, the debt accumulation schedule is further to the left, crossing below point $\mathrm{C}$, and only the good equilibrium exists. When $b_{0}$ is sufficiently high, the debt accumulation schedule is further to the right, crossing above point D, and only a bad equilibrium exists. In that case default is unavoidable when $\tilde{s}=s_{\text {low }}$.

\section{$2.2 \quad$ A Monetary Model}

We now extend the model to a monetary economy. The goods price level is $P_{t}$. $R_{t}$ is now the gross nominal interest rate and $r_{t}=R_{t} P_{t} / P_{t+1}$ the gross real interest rate. The central bank can set the interest rate $R_{t}$ and affect $P_{t}$. The coupons on government debt are now nominal. The number of bonds at time $t-1$ is $B_{t}$ and $B_{0}$ is given. We define $b_{t}=B_{t} / P_{t}$. The arbitrage equation with no default remains (4), while the government budget constraint for $t \neq T$ becomes

$$
Q_{t} B_{t+1}=\left((1-\delta) Q_{t}+\kappa\right) B_{t}-s_{t} P_{t}-Z_{t}
$$

where $s_{t}$ is now the real primary surplus, $s_{t} P_{t}$ the nominal surplus, and $Z_{t}$ is a nominal transfer from the central bank.

The central bank budget constraint is :

$$
Q_{t} B_{t+1}^{c}=\left((1-\delta) Q_{t}+\kappa\right) B_{t}^{c}+\left[M_{t}-M_{t-1}\right]-Z_{t}
$$

where $B_{t}^{c}$ are government bonds held by the central bank and are its sole assets. The value of central bank assets decreases with the depreciation of government bonds and payments $Z_{t}$ to the treasury. It is increased by the coupon payments and an expansion $M_{t}-M_{t-1}$ of monetary liabilities.

The balance sheets of the central bank and government are interconnected as most central banks pay a measure of net income (including seigniorage) to the Treasury as a dividend. ${ }^{10}$ We will therefore consider the consolidated government budget constraint by substituting the central bank constraint into the government budget constraint:

$$
Q_{t} B_{t+1}^{p}=\left((1-\delta) Q_{t}+\kappa\right) B_{t}^{p}-\left[M_{t}-M_{t-1}\right]-s_{t} P_{t}
$$

\footnotetext{
${ }^{10}$ See Hall and Reis (2013) for a discussion.
} 
where $B_{t}^{p}=B_{t}-B_{t}^{c}$ is government debt held by the general public. The consolidated government can reduce debt to the private sector by issuing monetary liabilities $M_{t}-M_{t-1}$.

Let $\widetilde{m}$ represent accumulated seigniorage between 0 and $T-1$ :

$$
\widetilde{m}=\frac{M_{T-1}-M_{T-2}}{P_{T-1}}+r_{T-2} \frac{M_{T-2}-M_{T-3}}{P_{T-2}}+\ldots+r_{0} r_{1} \ldots r_{T-2} \frac{M_{0}-M_{-1}}{P_{0}}
$$

Similarly, let $m^{p d v}$ denote the present discounted value of seigniorage revenues starting at date $T$ :

$$
m^{p d v}=\frac{M_{T}-M_{T-1}}{P_{T}}+\frac{1}{r_{T}} \frac{M_{T+1}-M_{T}}{P_{T+1}}+\frac{1}{r_{T} r_{T+1}} \frac{M_{T+2}-M_{T+1}}{P_{T+2}}+\ldots
$$

At time $T$ the real obligation of the government to bond holders is $\left[(1-\delta) Q_{T}+\right.$ $\kappa] b_{T}$. The no-default condition is $b_{T}^{p} \leq \tilde{b}$, with the latter now defined as

$$
\tilde{b}=\frac{s^{p d v}+m^{p d v}}{(1-\delta) Q_{T}+\kappa}
$$

where

$$
s^{p d v}=\left[1+\frac{1}{r_{T}}+\frac{1}{r_{T} r_{T+1}}+\ldots\right] s_{\text {low }}
$$

and $Q_{T}$ is equal to the present discounted value of coupons:

$$
Q_{T}=\frac{\kappa}{R_{T}}+\frac{(1-\delta) \kappa}{R_{T} R_{T+1}}+\frac{(1-\delta)^{2} \kappa}{R_{T} R_{T+1} R_{T+2}}+\ldots
$$

In analogy to the real model, the new pricing schedule becomes

$$
\begin{aligned}
Q_{T-1} & =\frac{(1-\delta) Q_{T}+\kappa}{R_{T-1}} & \text { if } b_{T}^{p} \leq \tilde{b} \\
& =\psi \frac{\min \left\{0, \zeta s^{p d v}+m^{p d v}\right\}}{R_{T-1} b_{T}^{p}}+(1-\psi) \frac{(1-\delta) Q_{T}+\kappa}{R_{T-1}} & \text { if } b_{T}^{p}>\tilde{b}
\end{aligned}
$$

Since $m^{p d v}$ can potentially be negative, in (19) the minimum return in the bad state is set at 0 . The new pricing schedule implies a relationship between $Q_{T-1}$ and $b_{T}$ that has the same shape as in the real model, but is now impacted by monetary policy through real and nominal interest rates, inflation, and seigniorage.

The debt accumulation schedule now becomes (see Appendix A):

$$
b_{T}^{p}=(1-\delta)^{T} \frac{B_{0}^{p}}{P_{T}}+\frac{P_{T-1}}{P_{T}} \frac{\chi^{\kappa} \kappa B_{0}^{p} / P_{0}-\chi^{s} \bar{s}-\widetilde{m}}{Q_{T-1}}
$$


where

$$
\begin{aligned}
\chi^{\kappa} & =\left[r_{T-2} \ldots r_{1} r_{0}+(1-\delta) r_{T-2} \ldots r_{1} \frac{P_{0}}{P_{1}}+(1-\delta)^{2} r_{T-2} \ldots r_{2} \frac{P_{0}}{P_{2}}+\ldots+(1-\delta)^{T-1} \frac{P_{0}}{P_{T-1}}\right] \\
\chi^{s} & =1+r_{T-2}+r_{T-2} r_{T-3}+\ldots+r_{T-2} \ldots r_{1} r_{0}
\end{aligned}
$$

The schedule again implies a negative relationship between $Q_{T-1}$ and $b_{T}$. Monetary policy shifts the schedule through its impact on interest rates, inflation, and seigniorage.

\subsection{The Impact of Monetary Policy}

Conventional monetary policy affects the paths of interest rates, prices, output and seigniorage, which in turn shifts the two schedules and therefore can affect the existence of self-fulfilling debt crises. The idea is to implement a monetary policy strategy conditional on expectations of sovereign default, which only happens in the crisis equilibrium. If this strategy is successful and credible, the crisis equilibrium is avoided altogether and the policy does not need to be implemented. It is therefore the threat of such a policy that may preclude the crisis equilibrium.

In terms of Figure 1, the crisis equilibrium is avoided when the debt accumulation schedule goes through point $\mathrm{C}$ or below. This is the case when

$\frac{\chi^{\kappa} \kappa B_{0} / P_{0}-\chi^{s} \bar{s}-\widetilde{m}}{s^{p d v}+m^{p d v}-\left((1-\delta) Q_{T}+\kappa\right)(1-\delta)^{T} B_{0} / P_{T}} r_{T-1} \leq \psi \frac{\min \left\{0, \zeta s^{p d v}+m^{p d v}\right\}}{s^{p d v}+m^{p d v}}+1-\psi$

Note that point $\mathrm{C}$ itself is not on the price schedule as its lower section starts for $b_{t}>\tilde{b}$. It is therefore sufficient that this condition holds as an equality, which corresponds to point $\mathrm{C}$. The central bank can impact this condition through both ex ante policies, taking place between 0 and $T-1$, and ex post policies, taking place in period $T$ and afterwards. Ex-ante policies have the effect of shifting the debt accumulation schedule down, while ex-post policies shift the pricing schedule to the right.

Conventional monetary policy can affect the existence of a default equilibrium through inflation, real interest rates, seigniorage and output. Inflation reduces the real value of nominal coupons on the debt outstanding at time 0. Ex-ante policy in the form of inflation prior to time $T$ reduces the real value of coupon payments both before and after $T$. This is captured respectively through $\chi^{\kappa}$ in the numerator of (21) and the term $B_{0} / P_{T}$ in the denominator in (21). Inflation after time $T$ only 
reduces the real value of coupons after $T$, which is reflected in a lower value of $Q_{T}$ in the denominator.

Reducing real interest rates lowers the cost of new borrowing. For ex-ante policy this is captured through both $\chi^{\kappa}$ and $\chi^{s}$ in the numerator of (21), which represents the accumulated new borrowing from 0 to $T$. For ex-post policy it shows up through a rise in $s^{p d v}$ in the denominator of (21). ${ }^{11}$ Expansionary monetary policy can also lead to a rise in seigniorage. Seigniorage prior to time $T$ reduces the numerator of the left hand side of $(21)$, while seigniorage after time $T$ raises the denominator. Finally, we will also consider an extension where monetary policy can have a favorable effect through output. If we allow the primary surplus to be pro-cyclical, expansionary monetary policy that raises output will raise primary surpluses.

Beyond these implications of conventional monetary policy, we will also consider unconventional monetary policy whereby the money supply is expanded beyond the satiation level, which happens at the zero lower bound. Since the impact of such policies is not immediately transparent from (21), we will postpone a discussion until Section 5 .

\section{A Basic New Keynesian Model}

We consider a standard New Keynesian model based on Galí (2008, ch. 3), with three extensions suggested by Woodford (2003): i) habit formation; ii) price indexation; iii) lagged response in price adjustment. These extensions are standard in the monetary DSGE literature and are introduced to generate more realistic responses to monetary shocks. The main effect of these extensions is to generate a delayed impact of a monetary policy shock on output and inflation, leading to the humped-shaped response seen in the data.

\footnotetext{
${ }^{11}$ There is one more subtle real interest rate rate effect, which is specific to the assumption that the central bank knows exactly when the default decision is made. By reducing the real interest rate $r_{T-1}$ the central bank can offset the negative impact of expected default on $Q_{T-1}$. This is captured through the last term on the left hand side of (21).
} 


\subsection{Households}

With habit formation, households maximize

$$
E_{0} \sum_{t=0}^{\infty} \beta^{t}\left(\frac{\left(C_{t}-\eta C_{t-1}\right)^{1-\sigma}}{1-\sigma}-\frac{N_{t}^{1+\phi}}{1+\phi}-z \iota_{t}\right)
$$

where total consumption $C_{t}$ is

$$
C_{t}=\left(\int_{0}^{1} C_{t}(i)^{1-\frac{1}{\varepsilon}} d i\right)^{\frac{\varepsilon}{\varepsilon-1}}
$$

and $N_{t}$ is labor and $z$ is a default cost. We have $\iota_{t}=0$ if there is no default at time $t$ and $\iota_{t}=1$ if there is default. The default cost does not affect households' decisions, but provides an incentive for authorities to avoid default. Habit persistence, measured by $\eta$, is a common feature in NK models to generate a delayed response of expenditure and output.

The budget constraint is

$$
\begin{aligned}
& P_{t} C_{t}+D_{t+1}+Q_{t} B_{t+1}^{p}+M_{t}= \\
& W_{t} N_{t}+\Pi_{t}-f\left(M_{t}, Y_{t}^{n}\right)+R_{t-1} D_{t}+R_{t-1}^{g} Q_{t-1} B_{t}^{p}+M_{t-1}-T_{t}
\end{aligned}
$$

Here $D_{t+1}$ are holdings of one-period bonds that are in zero net supply. $P_{t}$ is the standard aggregate price level and $W_{t}$ is the wage level. $\Pi_{t}$ are firms profits distributed to households and $T_{t}$ are lump-sum taxes. We will abstract from government consumption, so that the primary surplus is $P_{t} s_{t}=T_{t} . f\left(M_{t}, Y_{t}^{n}\right)$ is a transaction cost, where $Y_{t}^{n}=P_{t} Y_{t}$ is nominal GDP and $\partial f / \partial M \leq 0$.

The first-order conditions with respect to $D_{t+1}$ and $B_{t+1}^{p}$ are

$$
\begin{aligned}
\widetilde{C}_{t} & =\beta E_{t} R_{t} \frac{P_{t}}{P_{t+1}} \widetilde{C}_{t+1} \\
\widetilde{C}_{t} & =\beta E_{t} R_{t}^{g} \frac{P_{t}}{P_{t+1}} \widetilde{C}_{t+1}
\end{aligned}
$$

where

$$
\widetilde{C}_{t} \equiv\left(C_{t}-\eta C_{t-1}\right)^{-\sigma}-\eta \beta E_{t}\left(C_{t+1}-\eta C_{t}\right)^{-\sigma}
$$

The combination of (25) and (26) gives the arbitrage equations (4), (18), and (19). This is because government default, which lowers the return on government 
bonds, does not affect consumption due to Ricardian equivalence. ${ }^{12}$

Let $Y_{t}$ denote real output and $c_{t}, y_{t}$ and $y_{t}^{n}$ denote logs of consumption, output and the natural rate of output. Using $c_{t}=y_{t}$, and defining $x_{t}=y_{t}-y_{t}^{n}$ as the output gap, log-linearization of the Euler equation (25) gives the dynamic IS equation

$$
\tilde{x}_{t}=E_{t} \tilde{x}_{t+1}-\frac{1-\beta \eta}{\sigma}\left(i_{t}-E_{t} \pi_{t+1}-r^{n}\right)
$$

where

$$
\tilde{x}_{t}=x_{t}-\eta x_{t-1}-\beta \eta E_{t}\left(x_{t+1}-\eta x_{t}\right)
$$

Here $i_{t}=\ln \left(R_{t}\right)$ will be referred to as the nominal interest rate and $r^{n}=-\ln (\beta)$ is the natural rate of interest. The latter uses our assumption below of constant productivity, which implies a constant natural rate of output.

\subsection{Firms}

There is a continuum of firms on the interval $[0,1]$, producing differentiated goods. The production function of firm $i$ is

$$
Y_{t}(i)=A N_{t}(i)^{1-\alpha}
$$

We follow Woodford (2003) by assuming firm-specific labor.

Calvo price setting is assumed, with a fraction $1-\theta$ of firms re-optimizing their price each period. In addition, it is assumed that re-optimization at time $t$ is based on information from date $t-d$. This feature, adopted by Woodford (2003), is in the spirit of the model of information delays of Mankiw and Reis (2001). It has the effect of a delayed impact of a monetary policy shock on inflation, consistent with the data. ${ }^{13}$ Analogous to Christiano et al. (2005), Smets and Wouters (2003) and many others, we also adopt an inflation indexation feature in order to generate more persistence of inflation. Firms that do not re-optimize follow the simple indexation rule

$$
\ln \left(P_{t}(i)\right)=\ln \left(P_{t-1}(i)\right)+\gamma \pi_{t-1}
$$

\footnotetext{
${ }^{12}$ When substituting the consolidated government budget constraint $Q_{t} B_{t+1}^{p}=R_{t}^{g} Q_{t-1} B_{t}^{p}-$ $\left(M_{t}-M_{t-1}\right)-T_{t}$ into the household budget constraint (24), and imposing asset market equilibrium, we get $C_{t}=Y_{t}$, which is real GDP and unaffected by default. Here we assume that the transaction cost $f\left(M_{t}, Y_{t}^{n}\right)$ is paid to intermediaries that do not require real resources and return their profits to households. It is therefore included in $\Pi_{t}$.

${ }^{13}$ This feature can also be justified in terms of a delay by which newly chosen prices go into effect.
} 
where $\pi_{t-1}=\ln P_{t-1}-\ln P_{t-2}$ is aggregate inflation one period ago.

Leaving the algebra to the Technical Appendix, these features give the following Phillips curve (after linearization):

$$
\pi_{t}=\gamma \pi_{t-1}+\beta E_{t-d}\left(\pi_{t+1}-\gamma \pi_{t}\right)+E_{t-d}\left(\omega_{1} x_{t}+\omega_{2} \tilde{x}_{t}\right)
$$

where

$$
\begin{aligned}
\omega_{1} & =\frac{1-\theta}{\theta}(1-\theta \beta) \frac{\phi+\alpha}{1-\alpha+(\alpha+\phi) \varepsilon} \\
\omega_{2} & =\frac{1-\theta}{\theta}(1-\theta \beta) \frac{1-\alpha}{1-\alpha+(\alpha+\phi) \varepsilon} \frac{\sigma}{(1-\eta \beta)(1-\eta)}
\end{aligned}
$$

\subsection{Money Demand}

Most of the conventional monetary policy results we report are for a cashless economy. But to consider the additional role of seigniorage we use a convenient form of the transaction cost that gives rise to a standard specification for money demand when $i_{t}>0\left(m_{t}=\ln \left(M_{t}\right)\right)^{14}$ :

$$
m_{t}=\alpha_{m}+p_{t}+y_{t}-\alpha_{i} i_{t}
$$

When $i_{t}$ is close to zero, money demand reaches the satiation level $\alpha_{m}+p_{t}+y_{t}$. Under conventional monetary policy we assume that money supply does not go beyond the satiation level, so that there is a direct correspondence between the chosen interest rates and money supply.

\subsection{Monetary Policy}

We follow most of the literature by using a quadratic approximation of utility. Conditional on avoiding the default equilibrium, the central bank then minimizes the following objective function:

$$
E_{0} \sum_{t=0}^{\infty} \beta^{t}\left\{\mu_{x}\left(x_{t}-\nu x_{t-1}\right)^{2}+\mu_{\pi}\left(\pi_{t}-\gamma \pi_{t-1}\right)^{2}\right\}
$$

\footnotetext{
${ }^{14}$ The transaction cost $f\left(M_{t}, Y_{t}^{n}\right)=\alpha_{0}+M_{t}\left(\ln \left(\frac{M_{t}}{P_{t} Y_{t}}\right)-1-\alpha_{m}\right) / \alpha_{i}$ gives rise to money demand (32). This function applies for values of $M_{t}$ where $\partial f / \partial M \leq 0$. Once the derivative becomes zero, we reach a satiation level and we assume that the transaction cost remains constant for larger $M_{t}$.
} 
where $\nu, \mu_{x}$ and $\mu_{\pi}$ a function of model parameters (see the Technical Appendix for the derivation). The central bank chooses the optimal path of nominal interest rates over $H>T$ periods. After that, we assume an interest rate rule as in Clarida et al. (1999):

$$
i_{t}-\bar{\imath}=\rho\left(i_{t-1}-\bar{\imath}\right)+(1-\rho)\left(\psi_{\pi} E_{t} \pi_{t+1}+\psi_{y} x_{t}\right)
$$

where $\bar{\imath}=-\ln (\beta)$ is the steady state nominal interest rate. We will choose $H$ to be large. Interest rates between time $T$ and $H$ involve ex-post-policy. ${ }^{15}$

Optimal policy is chosen conditional on two types of constraints. The first is the ZLB constraint that $i_{t} \geq 0$ for all periods. In the good equilibrium that is the only constraint and the optimal policy implies $i_{t}=\bar{\imath}$ each period, delivering zero inflation and a zero output gap. However, conditional on expectations of default that raise default premia, the central bank will engage in expansionary policy that is just sufficient to avoid the self-fulfilling bad equilibrium, so that (21) is satisfied as an equality. Graphically, this means that the debt accumulation schedule goes through point $\mathrm{C}$ in Figure 1.

Using the NK Phillips curve (31), the dynamic IS equation (27), and the policy rule (34) after time $H$, we solve for the path of inflation and output gap conditional on the set of $H$ interest rates chosen. We then minimize the welfare cost (33) over the $H$ interest rates subject to $i_{t} \geq 0$ and (21) as an equality.

\subsection{Calibration}

We consider one period to be a quarter and normalize the constant productivity $A$ such that the natural rate of output is equal to 1 annually ( 0.25 per quarter). The other parameters are listed in Table 1. The left panel shows the parameters from the LW model, while the right panel lists the parameters that pertain to the New Keynesian part of the model.

Consider first the LW parameters. We set $\beta=0.99$, implying a $4 \%$ annualized interest rate. A key parameter, which we will see has an impact on the results, is $\delta$. In the benchmark parameterization we set it equal to 0.05 , which implies a government debt duration of 4.2 years. This is typical in the data. For example, OECD estimates of the Macauley duration in 2010 are 4.0 in the US and 4.4 for the average of the five European countries that experienced a sovereign debt crisis

\footnotetext{
${ }^{15}$ Since $H$ will be large, the precise policy rule after $H$ does not have much effect on the results.
} 
(Greece, Italy, Spain, Portugal and Ireland). The coupon is determined such that $\kappa=1 / \beta-1+\delta$.

The other parameters, $T$ and the fiscal surplus parameters, do not have a direct empirical counterpart, but are chosen so that there is a broad range of self-fulfilling equilibria. If the range of initial debt $B_{0}$ for which multiple equilibria are feasible is very narrow, the entire problem would be a non-issue.

The range of $B_{0}$ for which there are multiple equilibria under passive monetary policy $\left(i_{t}=\bar{\imath}\right)$ is $\left[B_{\text {low }}, B_{\text {high }}\right]$, where ${ }^{16}$

$$
\begin{aligned}
& B_{\text {low }}=\frac{\beta}{1-\beta} \frac{(\psi \zeta+1-\psi) \beta^{T} s_{\text {low }}+\left(1-\beta^{T}\right) \bar{s}}{1-(1-\zeta)(1-\delta)^{T} \beta^{T} \psi} \\
& B_{\text {high }}=\frac{\beta}{1-\beta}\left(\beta^{T} s_{\text {low }}+\left(1-\beta^{T}\right) \bar{s}\right)
\end{aligned}
$$

Under the parameters in Table 1 this range is $[0.79,1.46]$. This means that debt is between $79 \%$ and $146 \%$ of GDP. This is not unlike debt of the European periphery hit by the 2010 crisis, where debt ranged from $62 \%$ in Spain to $148 \%$ in Greece. Note that the assumption $\bar{s}=-0.01$, corresponding to a $4 \%$ annual primary deficit, also corresponds closely to Europe, where the five periphery crisis countries had an average primary deficit of $4.4 \%$ in 2010 . We set $T=20$ for the benchmark, corresponding to 5 years. We will see in section 4.2 that there are other parameter choices that lead to the same values of $B_{\text {low }}$ and $B_{\text {high }}$ without much effect on results.

The New Keynesian parameters are standard in the literature. The first 5 parameters correspond exactly to those in Gali (2008). The habit formation parameter, the indexation parameter and the parameters in the interest rate rule are all the same as in Christiano et al. (2005). We take $d=2$ from Woodford (2003, p. 218-219), which also corresponds closely to Rotemberg and Woodford (1997). This set of parameters implies a response to a small monetary policy shock under the Taylor rule that is similar to the empirical VAR results reported by Christiano et al. (2005). The level of output and inflation at their peak correspond exactly to that in the data. Both the output and inflation response is humped shaped like the data, although the peak response (quarter 6 and 3 respectively for inflation and output) occurs a bit earlier than in the data. We discuss the two money demand parameters in section 4.3, where we consider the role of seigniorage.

\footnotetext{
${ }^{16}$ These values lead to equilibria at points $C$ and $D$ in Figure 1.
} 


\section{Can Monetary Policy Credibly Avoid a Debt Crisis?}

The optimal monetary policy that we have described is credible as long as the welfare cost associated with inflation and non-zero output gaps is less than the cost of default. In reporting the results, we will mainly focus on the inflation cost. We do so for two reasons. First, the cost of default is hard to measure, including reputational costs, trade exclusion costs, costs through the financial system and political costs. In addition, even within our model the cost of inflation is very sensitive to parameters that otherwise have very little effect on optimal inflation. Second, we will see that the key message that an excessive amount of inflation is needed avoid a self-fulfilling default, is very robust and not affected by parameter assumptions that significantly affect the welfare cost in the model. ${ }^{17}$

We will first consider optimal monetary policy in a cashless economy where we abstract from seigniorage. After considering the benchmark parametrization, we show that the results are robust to significant changes in parameters. We finally consider seigniorage and extensions with a pro-cyclical fiscal surplus and uncertainty about $T$, none of which change the findings.

\subsection{Results under Benchmark Parameterization}

Figure 2 shows the dynamics of inflation under optimal policy under the benchmark parameterization for $H=40$ (which we assume throughout). The results are shown for various levels of $B_{0}$. The optimal path for inflation is hump shaped. Optimal inflation gradually rises, both due to rigidities and because the welfare cost (33) depends on the change in inflation. Eventually optimal inflation decreases as it becomes less effective over time when the original debt depreciates and is replaced by new debt that incorporates inflation expectations. When $B_{0}=B_{\text {middle }}=$ 1.12 , which is exactly in the middle of range of debt levels giving rise to multiple

\footnotetext{
${ }^{17}$ At a deeper level, a problem is that there is no consensus on what the exact welfare costs of inflation and output gap are. Inflation costs depend significantly on the type of price setting (see Ambler (2007) for a discussion of Taylor pricing versus Calvo pricing). Inflation costs are also broader than the inefficiencies associated with relative price changes that inflation induces. In the model the inflation cost would be zero if all firms raised prices simultaneously. It is also well known that the representative agent nature of the model understates the welfare costs of non-zero output gaps.
} 
equilibria, the maximum inflation rate reaches $23.8 \%$. Inflation is over $20 \%$ for 4 years, over $10 \%$ for 8 years and the price level ultimately increases by a factor 5.3 .

Such high inflation is implausible. Inflation needed to avoid default gets even much higher for higher debt levels. When $B_{0}$ reaches the upper bound $B_{\text {high }}$ for multiple equilibria, the maximum inflation rate is close to $47 \%$ and ultimately the price level increases by a factor 25 ! Only when $B_{0}$ is very close to the lower bound for multiplicity, as illustrated for $B_{0}=0.8$, is little inflation needed.

In order to understand why so much inflation is needed, first consider a rather extreme experiment where all of the increase in prices happens right away in the first quarter. This cannot happen in the NK model, so assume that prices are perfectly flexible, the real interest rate is constant at $1 / \beta$ and the output gap remains zero. When $B_{0}=B_{\text {middle }}=1.12$, the price level would need to rise by $42 \%$. This is needed to lower debt so that we are no longer in the region where multiple equilibria are possible. Of course such a policy, even if possible, is not plausible either as it would involve an annualized inflation rate for that quarter of $168 \%$.

In reality inflation will be spread out over a period of time, both because sticky prices imply a gradual change in prices and because it is optimal from a welfare perspective not to have the increase in the price level happen all at once. However, such a delay increases the ultimate increase in the price level that is needed. As the time zero debt depreciates (is repaid), inflation quickly becomes less effective as it only helps to reduce the real value of coupons on the original time zero debt. More inflation is then needed to avoid the default equilibrium.

Inflation may be limited to the extent that lower real interest rates, by lowering the costs of borrowing, help to avoid the default equilibrium. But the benefit from lower real interest rates turns out to be limited. Under the benchmark parameterization the real interest rate goes to zero for two quarters, since we reach the ZLB and inflation is initially zero, but after that it soon goes back to its steady state. In order to understand why this result is more general than the specific parameterization here, consider the consumption Euler equation, which in linearized form implies (27). It is well known that without habit formation $(\eta=0)$ this can be solved as

$$
x_{0}=-\frac{1}{\sigma} \sum_{t=0}^{\infty} E_{0}\left(r_{t}-r^{n}\right)
$$

This precludes a large and sustained drop in the real interest rate as it would imply 
an enormous and unrealistic immediate change in output at time zero, especially with $\sigma=1$ as often assumed.

For the benchmark parameterization, where $\sigma=1$ and $\eta=0.65$, we derive an analogous expression in the Technical Appendix. Removing the expectation operator and the $r^{n}$ for convenience, we have

$x_{0}=-0.58 r_{0}-0.73 r_{1}-0.83 r_{2}-0.89 r_{3}-0.93 r_{4}-0.95 r_{5}-0.97 r_{6}-0.98 r_{7}-0.99 r_{8}-\ldots$

Subsequent coefficients are very close to -1 . For the path of real interest rates under optimal policy this implies $x_{0}=0.0157$. This translates into an immediate increase in output of $6.3 \%$ on an annualized basis, which is already pushing the boundaries of what is plausible.

\subsection{Sensitivity Analysis}

We now consider changes to both the LW and NK parameters. An issue arises when changing the LW parameters as they affect the region $\left[B_{l o w}, B_{\text {high }}\right]$ for $B_{0}$ under which multiple equilibria arise. For example, when $T=10$, there is less time for a debt crisis to develop and a higher level of initial debt is needed to have a self-fulfilling crisis. Naturally the question that we address here has little content when this region $\left[B_{\text {low }}, B_{\text {high }}\right]$ is very narrow. This issue does not arise for the NK parameters, which leave this region unchanged.

We should first point out that the same region $\left[B_{l o w}, B_{\text {high }}\right]$ under which there are multiple equilibria under the benchmark parameterization applies to many other reasonable combinations of LW parameters. The left panel of Figure 3 shows combinations of $T, \bar{s}$ and $s_{\text {low }}$ that generate the same $B_{\text {low }}$ and $B_{\text {high }}$. The panel on the right shows that this has little effect on the path of optimal inflation. Varying $T$ from 10 to 30 , while adjusting $\bar{s}$ and $s_{\text {low }}$ to keep $B_{\text {low }}$ and $B_{\text {high }}$ unchanged, gives very similar paths for optimal inflation.

In Figure 4 and Table 2 we present results when varying one parameter at a time, but keeping $B_{0} / B_{\text {low }}$ the same as under the benchmark parameterization. Table 2 shows that $B_{\text {low }}$ and $B_{\text {high }}$ can be significantly affected by the LW parameters. But the results control for this by keeping $B_{0} / B_{\text {low }}=1.42$ as under the benchmark. For the LW parameters this implies values of $B_{0}$ that can be relatively closer to $B_{\text {low }}$ or $B_{\text {high }}$, dependent on their values for that parameter. ${ }^{18}$

\footnotetext{
${ }^{18}$ Only for $\zeta=0.7$ is $B_{0}$ now slightly above $B_{h i g h}$. For all other parameters the $B_{0}$ is within
} 
Each panel of Figure 4 reports optimal inflation for two values of a parameter, one higher and the other lower than in the benchmark. The last two columns of Table 2 report the price level after inflation and the maximum level of inflation. Figure 4 shows that for most parameters the optimal inflation path is remarkably little affected by the level of parameters. For example, optimal inflation is only slightly higher for $T=10$ than $T=30$. When $T$ is low, ex-post policies will be much more important than for higher values of $T$, but the overall impact on inflation is similar. Also notice that setting the probability $\psi$ of the bad state equal to 1 has little effect on the results.

There are three parameters, $\delta, \gamma$ and $d$, for which there are more significant differences. A lower debt depreciation $\delta$, which implies a longer maturity of debt, implies lower inflation. The reason is that inflation is effective for a longer period of time as the time 0 debt depreciates more slowly. But even when $\delta=0.025$, so that the duration is 7.2 years, optimal inflation is still above $10 \%$ for 6.5 years and the price level ultimately triples. A lower value for the lag in price adjustment, $d$, also allows for a lower inflation rate. With $d=0$ it is possible to increase inflation from the start, when debt deflation is the most powerful. But even with $d=0$, optimal inflation still peaks close to $20 \%$ and the price level still more than quadruples as a result of years of inflation. No matter what the parameter values, an implausibly high level of inflation is needed to avert a self-fulfilling debt crisis.

Finally, we also see a clear difference when we lower the inflation indexation parameter $\gamma$. Lower indexation reduces inflation persistence. But more importantly, it directly affects optimal policy through (33). With $\gamma=1$, only changes in inflation matter, while with $\gamma<1$ the level of inflation is also undesirable. To avoid higher inflation levels, the central bank takes advantage of the real interest rate channel to avoid the bad equilibrium. But the sharp drop in the real interest rate leads to an unrealistic output response: with $\gamma=0.9$, output increases at an annual rate of $24 \%$ in the first quarter. The same happens when we set $\gamma=d=\eta=0$ as in the Gali (2008) textbook model. In that case inflation starts at $23 \% \mathrm{APR}$ in the first quarter, but the ultimate increase in the price level is now much less, only $66 \%$. Inflation, while still substantial, is again limited in this case because of a sharp drop in real interest rates. There is now an incredulous $25 \%$ increase in output in the first quarter, which is a $100 \%$ annualized growth rate. the interval for $B_{0}$ generating multiple equilibria. 
Introducing additional features that limit such unrealistic changes in the level of output would again generate significantly higher inflation rates.

A couple of comments are in order about welfare versus inflation. As already pointed out, the welfare cost is very sensitive to NK parameters even when inflation is little affected. For example, the benchmark case gives a welfare cost of $2.8 \%$, measured as a one year percentage drop in consumption or output that generates the same drop in welfare. This seems quite small. But when we increase $\theta$ from 0.66 to 0.8 , the welfare cost more than triples to 8.7 , with very little difference in optimal inflation. If we adopt the textbook Gali model, where $\gamma=d=\eta=0$, the welfare cost is a staggering $85 \%$ and would be even much larger if we restricted the massive increase in output in the first quarter.

The welfare criterion depends significantly on the specific model that maps the chosen interest rates into inflation and output. But even if we substantially changed the NK model (beyond changes in parameters), the government is still trying to satisfy the no default constraint. The key message is that this constraint cannot be satisfied for a remotely credible path of inflation and plausible path of output.

\subsection{Seigniorage and Other Extensions}

We now discuss how the results are affected when we introduce seigniorage, a pro-cyclical primary surplus and uncertainty about $T$. So far we have assumed a cashless economy. In order to consider seigniorage, we need to make an assumption about the semi-elasticity $\alpha_{i}$ of money demand. Seigniorage revenue is larger for lower values of $\alpha_{i}$ as that leads to a smaller drop in real money demand when inflation rises. Estimates of $\alpha_{i}$ vary a lot, from as low as 6 in Ireland (2009) to as high as 60 in Bilson (1978). ${ }^{19}$ The biggest effect from seigniorage therefore comes from the lowest value $\alpha_{i}=6$. But even in that case the effect is limited. When $B_{0}=B_{\text {middle }}$, the maximum inflation rate is reduced from $23.8 \%$ to $19.9 \%$ and the price level ultimately increases by a factor 4.1 instead of $5.3 .^{20}$ Here we have

\footnotetext{
${ }^{19}$ Lucas (2000) finds a value of 28 when translated to a quarterly frequency. Engel and West (2005) review many estimates that also fall in this range.

${ }^{20}$ We calibrate $\alpha_{m}$ to the U.S., such that the satiation level of money corresponds to the monetary base just prior to its sharp rise in the Fall of 2008 when interest rates approached the ZLB. At that time the velocity of the monetary base was 17 . This gives $\alpha_{m}=-1.45$. The velocity is $4 P_{t} Y_{t} / M_{t}$ as output needs to be annualized, which is equal to $4 e^{-\alpha_{m}}$ at the satiation
} 
assumed that the money supply cannot go beyond the satiation level, a case we consider in the next section with unconventional monetary policy. There is clearly some benefit from conventional seigniorage, but quantitatively it is small and does not change our conclusion that an excessive amount of inflation is needed to avoid the crisis equilibrium. This result is consistent with Reis (2013) and Hilscher et al. (2014). As Reis (2013) puts it, "In spite of the mystique behind the central bank's balance sheet, its resource constraint bounds the dividends it can distribute by the present value of seigniorage, which is a modest share of GDP".

Nominal rigidities also give the central bank control over the accumulation of debt through the level of output that affects the primary surplus. So far we have abstracted from this channel, but we now introduce a pro-cyclical primary surplus. From 0 through $T-1$ we have

$$
s_{t}=\bar{s}+\lambda\left(y_{t}-\bar{y}\right)
$$

where $\bar{y}$ is steady-state output. We similarly assume that $s_{\text {low }}$ is pro-cyclical: $s_{\text {low }}=\bar{s}_{\text {low }}+\lambda\left(y_{t}-\bar{y}\right)$. We set the value of the cyclical parameter of the fiscal surplus to $\lambda=0.1$, in line with empirical estimates. ${ }^{21}$

With this additional effect from an output increase, the required inflation decreases slightly. For $B_{0}=B_{\text {middle, }}$, the maximum inflation rate is reduced from $23.8 \%$ in the benchmark to $19.9 \%$. The increase in the price level after inflation is reduced from 5.3 under the benchmark to 4.0, which remains excessive. Optimal policy now gives more emphasis to raising output, leading to a first quarter increase that is $10 \%$ APR, pushing the boundary of what is plausible.

In the Technical Appendix we discuss one final extension, uncertainty about the date $T$ of the default decision. This significantly complicates the model and we only consider two possible values, $T_{1}$ and $T_{2}$, which occur with probabilities $p$ and $1-p$. The key results remain the same. As one might expect, the range for $B_{0}$ over which there are multiple equilibria is now in between that for the cases where $T=T_{1}$ and $T=T_{2}$ without uncertainty. Monetary policy after $T_{1}$ is now contingent on whether there was a default decision at $T_{1}$ or not. The key conclusion that an excessive amount of inflation is needed to avoid default (at both $T_{1}$ and $T_{2}$ ) remains unaltered.

level.

${ }^{21}$ Note that since $\bar{Y}=0.25$ for quarterly GDP, the specification implies that $\Delta s=0.4 \Delta Y$. This is consistent for example with estimates by Girouard and André (2005) for the OECD. 


\section{Unconventional Monetary Policy}

In this section we consider what the central bank can achieve through a significant increase in money supply beyond the satiation level. We will argue that this is only helpful in averting a self-fulfilling crisis if the economy is at a structural ZLB, where the natural real interest rate is zero, for a long time.

\section{$5.1 \quad$ Seigniorage}

It is first useful to point out that expanding the money supply beyond the satiation level does not provide any support to the government through seigniorage. The present discounted value of seigniorage is

$$
\frac{1}{r_{0} \ldots r_{T-2}} \tilde{m}+\frac{1}{r_{0} \ldots r_{T-1}} m^{p d v}=-\frac{M_{-1}}{P_{0}}+\sum_{t=0}^{\infty} \frac{1}{r_{0} \ldots r_{t}}\left(R_{t}-1\right) \frac{M_{t}}{P_{t+1}}
$$

An increase in the money supply beyond the satiation level has no effect on interest rates, which are already zero, and on prices. Money balances expand, but they are multiplied by a zero nominal interest rate $R_{t}-1$ at the ZLB. The present discounted value of seigniorage is therefore unaffected. One can think of seigniorage in two ways. One is the real value of the changes in monetary liabilities. In that context, any expansion of money beyond the satiation level will eventually be unwound as the economy will not be at the ZLB forever. Positive seigniorage is therefore eventually offset later by negative seigniorage. Alternatively, seigniorage can be thought of as the saving to the government from not having to pay interest on monetary liabilities. But this saving is zero when the nominal interest rate is 0 .

\subsection{Liquidity Support and Buyback Policies}

We consider two specific policies that both reduce government debt held by the private sector and therefore default premia that the government pays on its debt. It is these default premia that are at the heart of the self-fulfilling crisis.

The first is a liquidity support policy whereby the central bank provides the government with liquidity equal to $\kappa B_{t}-s_{t} P_{t}$ from time 0 through $\tilde{T}-1$. This quantity corresponds to the new debt issued each period. Under the liquidity support policy, the government avoids paying default premia on new debt in the 
bad equilibrium. This policy implies that the consolidated government issues new monetary liabilities of $\kappa B_{t}-s_{t} P_{t}$ in period $t$.

The increase in money supply following from this policy goes well beyond the satiation level. ${ }^{22}$ When the debt to GDP ratio is 1, it implies a seigniorage of $28 \%$ per year under the benchmark. We will therefore be at the ZLB as long as this policy is in place. However, as long as the natural real interest rate is positive, or at least not zero forever, an expansion of money beyond the satiation level will be impossible to maintain. We assume that at time $\tilde{T}$, the end of the policy, the expansion of monetary liabilities is replaced by new debt.

The second policy is a "buyback policy," whereby the consolidated government (i) buys back government bonds in exchange for monetary liabilities prior to time $T$ and (ii) reverses this at time $\tilde{T}$ by replacing the increase in monetary liabilities with new debt. For simplicity we will assume that the buyback happens all at once, although this is not important.

\subsection{Policy under Structural Zero Lower Bound}

It is instructive to first consider the case where we are at a structural ZLB, so that the natural real interest rate is zero or below, while the policies discussed above are implemented. To illustrate this, assume that $\beta=1$ through period $\bar{T}$, after which $\beta$ is a constant less than 1 .

In this case, assuming $\bar{T} \geq T$, the default equilibrium can be avoided through the liquidity support policy we described when this policy lasts through time $T-1$ $(\tilde{T}=T)$. A formal proof of this is provided in Appendix B. The policy has no cost as we are already at the ZLB before the policy is implemented, and therefore prices and output are unaffected. The default equilibrium is avoided because the government does not need to pay default premia from time 0 until time $T$. Instead of issuing new debt on which default premia are paid, it now issues monetary liabilities.

However, when $\bar{T}<T$ the monetary expansion beyond the satiation level needs to be reversed prior to time $T$ if we wish to avoid the costs associated with changes in prices and output gap. With $\tilde{T}<T$ under either the liquidity support or buyback policies, default is not averted as seigniorage is not affected. $m^{p d v}$ is

\footnotetext{
${ }^{22}$ In section section 4.3 we have estimated the satiation level to be about $4 \%$ of GDP.
} 
unchanged as the policy occurs prior to time $T$ and $\tilde{m}$ can be written as

$$
\tilde{m}=\frac{M_{T-1}}{P_{T-1}}-r_{0} \ldots r_{T-2} \frac{M_{-1}}{P_{0}}+r_{1} \ldots r_{T-2}\left(R_{0}-1\right) \frac{M_{0}}{P_{1}}+\ldots+\left(R_{T-2}-1\right) \frac{M_{T-2}}{P_{T-1}}
$$

$\tilde{m}$ does not change as any money balances that are beyond the satiation level are multiplied by zero $\left(R_{t}=1\right)$ and $M_{T-1}$ does not change (the money expansion is reversed prior to time $T$ ). Since neither the pricing nor the debt accumulation schedules are affected in that case, the same default equilibrium exists as before.

The intuition behind this result is as follows. On the one hand, the government does not need to pay default premia on monetary liabilities. On the other hand, there is an exactly offsetting loss that is a result of a gradual decline in the price of government bonds in the default equilibrium. Under the buyback policy, the government would therefore buy back its debt at a price higher than the price at which it later sells new debt (prior to time $T$ ). Under the liquidity support policy, the government sells new debt prior to time $T$ to replace its expanded money supply. The debt is sold at a lower price than the government would have received if it had sold new debt earlier instead of issuing monetary liabilities.

\subsection{Policy Outside a Structural ZLB}

Now assume that the economy is not at a structural ZLB. Therefore assume that $\beta<1$ is a constant as before and the natural real interest rate $r^{n}=-\ln (\beta)$ is positive. It is easy to see that neither the liquidity support nor buyback policies are effective if in place only through time $\tilde{T}<T-1$. We can think of these policies in two steps. The first step involves expanding the money supply to the satiation level. The second step involves a further expansion of money beyond the satiation level. The latter has no effect for the same reason that it has no effect under a structural ZLB. The first step also cannot credibly avoid a default as it can be no better than the optimal policy considered in section 4.3 when the money supply was restricted to be no larger than the satiation level.

For $\tilde{T} \geq T-1$ as well, neither of the two policies can credibly avoid the default equilibrium. First consider a liquidity support policy that lasts through time $T-1$. As already discussed, the required increase in monetary liabilities is well beyond the satiation level from the very start. The nominal interest rate is then lowered to 0 from period 0 to at least $T-1$. We argue that this is either impossible or excessively costly by generating substantial deflation and a steep recession. 
To see this, using the consumption Euler equation without habit formation for illustration, and setting the nominal interest rate at 0 for the first $T$ periods, we have

$$
E_{0} \sum_{t=1}^{T} \pi_{t}+\sigma E_{0}\left(x_{T}-x_{0}\right)=-T r^{n}
$$

With a $4 \%$ natural rate (benchmark parameterization), $\sigma=1$ and $T=20$, the right hand side is $-20 \%$. (42) then implies either a sharp drop in output or steep deflation. In general there will be a combination of the two. ${ }^{23}$ It is implausible that a central bank would wish to engineer a deep recession on purpose in order to avoid a government default. ${ }^{24}$

It is also hard to see how a buyback policy that ends at time $T$ or later could be effectively implemented when the natural real interest rate is positive. Appendix B shows that at the structural ZLB such a policy would avoid the default equilibrium without any costs. There are two problems with this policy though. The first problem is associated with time consistency and applies whether we are at the structural ZLB or not. This occurs when the debt buyback happens sufficiently close to time $T$, for example at $T-1$. In that case the government is already insolvent in the bad equilibrium. ${ }^{25}$ The only hope for the government to avoid default would be to buy back debt at the depressed low-equilibrium price and sell it again at $T$ at the high risk-free price. But if the capital gain arising from this policy could succeed in avoiding default, the price at the buyback time would already be at its risk-free level, so default could not be avoided. Thus, the government has no incentive to follow through its promise to buy at $T-1$. Since investors are aware of this, the bad equilibrium can arise at $t=0$.

If instead the debt buyback happens closer to time 0, when the government

\footnotetext{
${ }^{23}$ The output drop is larger with stronger downward nominal rigidities. Particularly wages are rigid downward, an aspect that is not captured in the model. Daly and Hobijn (2014) show that downward nominal wage rigidities bend the Phillips curve. During recessions, when the rigidities become more binding, they find that the labor market adjusts more through the unemployment margin than through wages.

${ }^{24}$ Moreover, it is not even guaranteed that this policy would succeed in achieving its objective. While the government will not need to pay default premia on new debt, deflation increases the real coupons on the original debt from period 0 , while a recession can significantly lower tax revenues.

${ }^{25} \mathrm{LW}$ show that the government becomes insolvent sometime between date 0 and $T$ as the debt accumulates due to default premia.
} 
is not yet insolvent, this problem would not arise. But, as already discussed in the context of the liquidity support policy, it would require lowering the nominal interest rate to 0 for a substantial period of time, which creates deflation and a deep recession.

\section{Discussion}

Here we briefly discuss three related questions. The first one is a proposal by Corsetti and Dedola (2014) that the central bank issue risk-free liabilities that are convertible into cash. Second, we ask why many highly indebted non-Eurozone countries with their own currencies have escaped such crises recently if our conclusion is correct that the central bank cannot play much of a role. Finally, we ask why a change in ECB policy in the summer of 2012 was successful in lowering sovereign debt spreads, which seemingly goes against our message that there is little that central banks can do.

Under the Corsetti-Dedola proposal government liabilities are replaced by central bank liabilities. When consolidating the accounts of the central government and central bank, there is in principle little difference between debt issued by the government and the central bank. Nothing stops investors from demanding

a default premium on non-monetary liabilities of the central bank. Convertibility into cash is not credible for the same reasons we discussed that simply replacing government debt with monetary liabilities does not help.

With regards to the second question, why countries with their own central banks seem to have escaped sovereign debt crises recently, there are many possible answers. The answer may partly be that since the end of 2008 many countries have been at a structural ZLB, which is the only case we identified where central bank policy may be effective. But the answer can also be that these countries are less exposed to self-fulfilling debt crises even with passive monetary policy when the market believes that their governments are more likely to make significant fiscal adjustments when needed. Other parameters of the model, such as higher expected recovery rates, may play a role as well. Even if there are multiple equilibria, at any point in time there may not be a trigger leading investors to coordinate on the bad equilibrium. The bottom line here is that there are many explanations that have nothing to do with whether these countries have their own currency. 
Regarding the last question, the analysis in this paper applies to a central bank that aims to avoid a self-fulfilling default by the central government. The situation where the central bank of a currency union aims to avoid sovereign default in periphery countries of the union is quite different. Specifically, the ECB could buy government bonds of the periphery countries that experience high default premia and sell government bonds of countries that are not subject to a sovereign debt crisis. No monetary liabilities need to be issued in the process, generating no inflation.

The ECB could keep interest rates on new debt of the periphery governments equal to their no-default levels and buy all new bonds that would otherwise be sold to the private sector at that low interest rate. The threat alone of doing so is sufficient, which is exactly what happened under the OMT policy in the summer of 2012 and the famous Draghi statement "to do whatever it takes". Such a threat was credible as such an intervention would not overwhelm the ECB. ${ }^{26}$ This explains why sovereign spreads quickly fell due to the change in policy. But such a policy applies to a periphery and is of no help if a central bank aims to avoid a self-fulfilling sovereign debt crisis associated with its central government. Analogously, it would not work if the ECB aimed to avoid a self-fulfilling sovereign debt crisis across the entire Eurozone.

\section{Conclusion}

Several recent contributions have derived analytical conditions under which the central bank can avoid a self-fulfilling sovereign debt crisis. Extreme central bank intervention, generating extraordinary inflation, would surely avoid a sovereign debt crisis. But the cost would be excessive, making such actions not credible. The aim of this paper has been to quantify this cost in order to better assess whether countries with their own currency (and therefore central bank) are less likely to be subject to such self-fulfilling debt crises.

To address this question, we have adopted a dynamic model with many realistic elements that make a quantitative assessment more meaningful. We introduced a

\footnotetext{
${ }^{26}$ For example, in 2010 the sum of all the periphery country government deficits together (Greece, Ireland, Portugal, Spain, Italy) amounted to $13 \%$ of the ECB balance sheet. And a self-fulfilling default can be avoided even if only a portion of these financing needs are covered by the ECB.
} 
New Keynesian model with nominal rigidities in which monetary policy has realistic effects on output and inflation. We introduced long-term bonds and calibrated the maturity to what is observed in many industrialized countries. We allowed for slow-moving debt crises that are a good representation of the recent European sovereign debt crisis. We have considered both conventional monetary policy that impacts inflation, real interest rates and output, and unconventional monetary policy that leads to a large expansion of the monetary base.

Overall our conclusion is that the ability to avert self-fulfilling crises is limited. Unless debt is close to the bottom of an interval where multiple equilibria occur, conventional policies involve very high inflation for a sustained period of time. Unconventional monetary policy is only useful when the economy is at the structural ZLB for a sustained length of time.

Several extensions are worthwhile considering for future work. We have focused on a closed economy. In an open economy monetary policy also affects the exchange rate, which affects relative prices and output. While we made some brief comments at the end, it would also be of interest to more explicitly consider a monetary union, where sovereign default may be limited to only a segment of the union. Finally, we have only considered one type of self-fulfilling debt crises, associated with the interaction between sovereign spreads and debt. It would be of interest to also consider rollover crises or even a combination of both types of crises. This also provides an opportunity to consider the optimal maturity of sovereign debt, which we have taken as given. 


\section{Appendix}

\section{A. Derivation of the Debt Accumulation Schedule.}

We derive the debt accumulation schedule in the general case of Section 2.4. The debt accumulation schedule in the cashless economy (Section 2.2) is a special case of this where $M_{t}=0$ at all times. We first derive a relationship between $Q_{0}$ and $Q_{T-1}$. Integrating forward the one-period arbitrage equation (4) from $t=1$ to $t=T-1$, we have:

$$
Q_{0}=A^{\kappa} \kappa+A^{Q} Q_{T-1}
$$

where

$$
\begin{aligned}
A^{\kappa} & =\frac{1}{R_{0}}+\frac{1-\delta}{R_{0} R_{1}}+\frac{(1-\delta)^{2}}{R_{0} R_{1} R_{2}}+\ldots+\frac{(1-\delta)^{T-2}}{R_{0} R_{1} R_{2} \ldots R_{T-2}} \\
A^{Q} & =\frac{(1-\delta)^{T-1}}{R_{0} R_{1} R_{2} \ldots R_{T-2}}
\end{aligned}
$$

Next consider the consolidated budget constraint (12):

$$
Q_{t} B_{t+1}^{p}=\left((1-\delta) Q_{t}+\kappa\right) B_{t}^{p}-v_{t}-s_{t} P_{t}
$$

where $v_{t}=\left[M_{t}-M_{t-1}\right]$. The government budget constraint at $t=0$ is:

$$
\frac{Q_{0} B_{1}^{p}}{P_{0}}=\left((1-\delta) Q_{0}+\kappa\right) b_{0}^{p}-\bar{s}-\frac{v_{0}}{P_{0}}
$$

For $1<t<T$

$$
\frac{Q_{t} B_{t+1}^{p}}{P_{t}}=r_{t-1} \frac{Q_{t-1} B_{t}^{p}}{P_{t-1}}-\bar{s}-\frac{v_{t}}{P_{t}}
$$

Using equations (48) and (47) and integrating forward, we obtain

$$
\begin{aligned}
& \frac{Q_{T-1} B_{T}^{p}}{P_{T-1}}=r_{T-2} \ldots r_{1} r_{0} \frac{Q_{0} B_{1}^{p}}{P_{0}}-\bar{s}\left(1+r_{T-2}+r_{T-2} r_{T-1}+\ldots+r_{T-2} r_{T-1} \ldots r_{1}\right) \\
& -\left[r_{1} \ldots r_{T-2} \frac{v_{1}}{P_{1}}+r_{2} \ldots r_{T-2} \frac{v_{2}}{P_{2}}+\ldots+\frac{v_{T-1}}{P_{T-1}}\right]
\end{aligned}
$$

Combining equation (49) with (47) and (43), we obtain:

$$
\begin{aligned}
\frac{Q_{T-1} B_{T}^{p}}{P_{T-1}}= & r_{T-2} \ldots r_{1} r_{0}(1-\delta) b_{0}^{p} Q_{0}+r_{T-2} \ldots r_{1} r_{0} \kappa b_{0}^{p} \\
& -\bar{s}\left(1+r_{T-2}+r_{T-2} r_{T-3}+\ldots+r_{T-2} \ldots r_{1} r_{0}\right) \\
& -\left[r_{0} \ldots r_{T-2} \frac{v_{0}}{P_{0}}+r_{1} \ldots r_{T-2} \frac{v_{1}}{P_{1}}+\ldots+\frac{v_{T-1}}{P_{T-1}}\right]
\end{aligned}
$$


Using equations (43)-(45), we can rewrite equation (50) as

$$
\begin{aligned}
\frac{Q_{T-1} B_{T}^{p}}{P_{T-1}}= & \frac{P_{0}}{P_{T-1}}(1-\delta)^{T} b_{0}^{p} Q_{T-1} \\
& +r_{T-2} \ldots r_{1} r_{0}\left[1+\frac{1-\delta}{R_{0}}+\frac{(1-\delta)^{2}}{R_{0} R_{1}}+\ldots+\frac{(1-\delta)^{T-1}}{R_{0} R_{1} R_{2} \ldots R_{T-2}}\right] \kappa b_{0}^{p} \\
& -\bar{s}\left(1+r_{T-2}+r_{T-2} r_{T-3}+\ldots+r_{T-2} \ldots r_{1} r_{0}\right) \\
& -\left[r_{0} \ldots r_{T-2} \frac{v_{0}}{P_{0}}+r_{1} \ldots r_{T-2} \frac{v_{1}}{P_{1}}+\ldots+\frac{v_{T-1}}{P_{T-1}}\right]
\end{aligned}
$$

Using the expression for $v_{t}$, the last term in brackets is equal to $\tilde{m}$ as defined in (13). This yields (20).

\section{B. Avoiding Self-fulfilling Default at a Structural ZLB}

Assume that the discount rate $\beta$ is 1 for $t=0, . ., \bar{T}$ with $\bar{T} \geq T-1$ and it is a constant $\beta<1$ for $t>\bar{T}$. Under this assumption the central bank can keep the interest rate zero through time $\bar{T}$, and raise it to $1 / \beta$ after time $\bar{T}$, while keeping inflation and the output gap at zero all along. So we have $R_{t}=1$ for $t=0, . ., \bar{T}$ and $R_{t}=1 / \beta$ for $t>\bar{T}$. The price level is always 1 . We then have $Q_{T}=\kappa \sum_{i=0}^{\bar{T}-T}(1-\delta)^{i}+(1-\delta)^{\bar{T}-T+1}$.

Using (41) we have $\tilde{m}=M_{T-1}-M_{-1}$. Let $\bar{M}$ be the level of money demand starting at $\bar{T}+1$, when we are no longer at the ZLB. Then $m^{p d v}=\bar{M}-M_{T-1}$. Define $\Delta M=M_{T-1}-M_{-1}$ and $d m=\bar{M}-M_{-1}$. Then $\tilde{m}=\Delta M$ and $m^{p d v}=d m-\Delta M$. Assuming that we are already at the ZLB at time $-1, d m$ is negative.

Using the results from section 2.4 , the pricing schedule is then

$$
\begin{aligned}
Q_{T-1} & =(1-\delta) Q_{T}+\kappa & & \text { if } B_{T}^{p} \leq \tilde{b} \\
& =\psi h(\Delta M)+(1-\psi)\left((1-\delta) Q_{T}+\kappa\right) & & \text { if } B_{T}^{p}>\tilde{b}
\end{aligned}
$$

where $h(\Delta M)=0$ if $\zeta s^{p d v}+d m-\Delta M \leq 0$ and otherwise $h(\Delta M)=\frac{\zeta s^{p d v}+d m-\Delta M}{B_{T}^{p}}$, and

$$
\tilde{b}=\frac{s^{p d v}+d m-\Delta M}{(1-\delta) Q_{T}+\kappa}
$$

The debt accumulation schedule is

$$
B_{T}^{p}=(1-\delta)^{T} B_{0}^{p}+\frac{\chi^{\kappa} \kappa B_{0}^{p}-T \bar{s}-\Delta M}{Q_{T-1}}
$$

Passive monetary policy takes the form $\Delta M=0$. The central bank then does not expand the money supply between -1 and $T-1$. Under passive monetary 
policy there are multiple equilibria when $B_{0}$ is within a range that we have called $\left[B_{\text {low }}, B_{\text {high }}\right]$. The condition $B_{0} \leq B_{\text {high }}$ implies that the debt accumulation schedule crosses at or below $(1-\delta) Q_{T}+\kappa$ when $B_{T}^{p}=\tilde{b}$ (point D in Figure 1) and $\Delta M=0$. This can be written as

$$
\frac{\chi^{\kappa} \kappa B_{0}^{p}-T \bar{s}}{\tilde{b}-(1-\delta)^{T} B_{0}^{p}} \leq(1-\delta) Q_{T}+\kappa
$$

Substituting the expression for $\tilde{b}$ with $\Delta M=0$, this becomes

$$
s^{p d v}+d m-(1-\delta)^{T} B_{0}^{p}\left((1-\delta) Q_{T}+\kappa\right) \geq \chi^{\kappa} \kappa B_{0}^{p}-T \bar{s}
$$

Now assume that $\Delta M \geq \chi^{\kappa} \kappa B_{0}^{p}-T \bar{s}$ conditional on a sunspot shock. We will show that this is a sufficient condition to avoid the bad equilibrium. If there were a bad equilibrium with default, we know from the pricing schedule that $Q_{T-1}<(1-\delta) Q_{T}+\kappa$. In that case the debt accumulation schedule, together with the assumption $\Delta M \geq \chi^{\kappa} \kappa B_{0}^{p}-T \bar{s}$, implies

$$
B_{T}^{p} \leq(1-\delta)^{T} B_{0}^{p}+\frac{\chi^{\kappa} \kappa B_{0}^{p}-T \bar{s}-\Delta M}{(1-\delta) Q_{T}+\kappa}
$$

It can be shown that the right hand side is less than or equal to $\tilde{b}$, so that $B_{T}^{p} \leq \tilde{b}$ and there cannot be a default equilibrium. The condition that the right hand side is less than $\tilde{b}$ is

$$
(1-\delta)^{T} B_{0}^{p}+\frac{\chi^{\kappa} \kappa B_{0}^{p}-T \bar{s}-\Delta M}{(1-\delta) Q_{T}+\kappa} \leq \frac{s^{p d v}+d m-\Delta M}{(1-\delta) Q_{T}+\kappa}
$$

Multiplying both sides by $(1-\delta) Q_{T}+\kappa$, we can rewrite this as (57), which holds if there are multiple equilibria under passive monetary policy.

Notice that $\Delta M=\chi^{\kappa} \kappa B_{0}^{p}-T \bar{s}$ is exactly the amount that implements the liquidity support policy described in Section 5. Alternatively, $\Delta M$ could be used to buy outstanding debt in the secondary market at any time before time $T$. The latter would be the buyback policy, also described in Section 5. 


\section{References}

[1] Aguiar, Mark, Manuel Amador, Emmanuel Fahri and Gita Gopinath (2013), "Crisis and Commitment: Inflation Credibility and the Vulnerability to Sovereign Debt Crisis," working paper, Harvard University.

[2] Ambler, Steve (2007), "The Costs of Inflation in New Keynesian Models," Bank of Canada Review, Winter 2007-2008, 5-14.

[3] Bilson, John F.O. (1978), "The Monetary Approach to the Exchange Rate: Some Empirical Evidence," International Monetary Fund Staff Papers 25(1), 48-75.

[4] Bhattarai, Saroj, Gauti Eggertsson, and Bulat Gafarov (2013), "Time Consistency and the Duration of Government Debt: A Signalling Theory of Quantitative Easing," working paper, Brown University.

[5] Calvo, Guillermo (1988), "Servicing the Public Debt: The Role of Expectations," American Economic Review 78(4), 647-661.

[6] Camous, Antoine and Russell Cooper (2014), "Monetary Policy and Debt Fragility," NBER Working Paper No. 20650.

[7] Christiano, L.J., M. Eichenbaum and C.L. Evans (2005), "Nominal Rigidities and the Dynamic Effects of a Shock to Monetary Policy," Journal of Political Economy 1(113), 1-45.

[8] Clarida, Richard, Jordi Gali and Mark Gertler (1999), "The Science of Monetary Policy: A New-Keynesian Perspective," Journal of Economic Literature $37,1661-1707$.

[9] Cohen, Daniel and Sebastian Villemot (2015), "Endogenous Debt Crises," Journal of International Money and Finance 51, 337-369.

[10] Cole, Harold L. and Tim Kehoe (2000), "Self-fulfilling Debt Crises," Review of Economic Studies 67, 91-116.

[11] Conesa, Juan Carlos and Timothy J. Kehoe (2015), "Gambling for Redemption and Self-Fulfilling Debt Crises," Minneapolis Fed Staff Report 465. 
[12] Corsetti, Giancarlo and Luca Dedola (2014), "The Mystery of the Printing Press: Monetary Policy and Self-Fulfilling Debt Crises," working paper, Cambridge University.

[13] Daly, Mary C. and Bart Hobijn (2014), "Downward Nominal Wage Rigidities Bend the Phillips Curve," San Francisco Fed Working Paper 2013-08.

[14] Gali, Jordi (2008), Monetary Policy, Inflation and the Business Cycle: An Introduction to the New Keynesian Framework, Princeton University Press, Princeton, NJ.

[15] de Grauwe, Paul (2011), "The Governance of a Fragile Eurozone" CEPS Working Documents, CEPS, Brussels.

[16] de Grauwe, Paul and Juemei Ji (2013), "Self-Fulfilling Crises in the Eurozone: An Empirical Test," Journal of International Money and Finance 34, 15-36.

[17] Eaton, Jonathan and Mark Gersovitz (1981), "Debt with Potential Repudiation: Theoretical and Empirical Analysis," Review of Economic Studies 48, 289-309.

[18] Engel, Charles and Kenneth D. West (2005), "Exchange Rates and Fundamentals," Journal of Political Economy 113(3), 485-517.

[19] Girouard, N. and C. André (2005), "Measuring Cyclically adjusted Budget Balances for OECD Countries," OECD Economics Department Working Papers, No. 434.

[20] Gomes, Joao, Urban Jerman and Lukas Schmid (2014), "Sticky Leverage," mimeo.

[21] Gros, Daniel (2012), "A simple model of multiple equilibria and default," CEPS Working Document No. 367.

[22] Hall, Robert E. and Ricardo Reis (2013), "Maintaining Central-Bank Solvency under New-Style Central Banking," working paper, Stanford University.

[23] Hatchondo, Juan Carlos and Leonardo Martinez (2009), "Long-Duration Bonds and Sovereign Default," Journal of International Economics 79, 117125. 
[24] Hilscher, Jens, Alon Raviv, and Ricardo Reis (2014), "Inflating Away the Public Debt? An Empirical Assessment," NBER Working Paper No. 20339.

[25] Ireland, Peter N. (2009), "On the Welfare Cost of Inflation and the Recent Behavior of Money Demand," American Economic Review 99(3), 1040-52.

[26] Jeanne, Olivier (2012), "Fiscal Challenges to Monetary Dominance in the Euro Area: A Theoretical Perspective," working paper, Johns Hopkins University.

[27] Jeanne, Olivier and Hou Wang (2013), "Fiscal Challenges to Monetary Dominance," working paper, Johns Hopkins University.

[28] Krugman, Paul (2013), "Currency Regimes, Capital Flows and Crises," IMF Mundell-Fleming Lecture.

[29] Leeper, Eric M. and Xuan Zhou (2013), "Inflation's Role in Optimal Monetary-Fiscal Policy," NBER Working Paper No. 19686.

[30] Lorenzoni, Guido and Ivan Werning (2014), "Slow Moving Debt Crises," working paper, Northwestern University.

[31] Lucas, Robert E. (2000), "Inflation and Welfare," Econometrica 68(2), 247274 .

[32] Miller, Marcus and Lei Zhang (2012), "Saving the Euro: Self-fulfilling Crisis and the Draghi Put," CEPR Discussion Paper 9976.

[33] Navarro, Gaston, Juan Pablo Nicolini and Pedro Teles (2014), "Sovereign Default: The Role of Expectations," mimeo.

[34] Reis, Ricardo (2013), "The Mystique Surrounding the Central Bank's Balance Sheet," American Economic Review, Papers and Proceedings 103(3), 134-140.

[35] Rotemberg, Julio and Michael Woodford (1997), "An Optimization Based Econometric Framework for the Evaluation of Monetary Policy," NBER Macroeconomics Annual 19977, 297-346.

[36] Sheedy, Kevin (2014), "Debt and Incomplete Financial Markets: A Case for Nominal GDP Targeting," Brookings Papers on Economic Activity, Spring 2014. 
[37] Smets, Frank and Rafael Wouters (2003), "An Estimated Dynamic Stochastic General Equilibria Model of the Euro Area," Journal of the European Economic Association 1(5), 1123-1175.

[38] Woodford, Michael (2003), "Interest Rates and Prices: Foundations of a Theory of Monetary Policy," Princeton University Press, Princeton, NJ. 


\begin{tabular}{|c|c|c|c|}
\hline \multicolumn{4}{|c|}{ Table 1 Calibration } \\
\hline \multicolumn{2}{|c|}{ Lorenzoni-Werning parameters } & \multicolumn{2}{|r|}{ New Keynesian parameters } \\
\hline Parameter & Description & Parameter & Description \\
\hline$\beta=0.99$ & discount rate & $\sigma=1$ & elasticity of intertemporal subsitution \\
\hline$\delta=0.05$ & coupon depreciation rate & $\phi=1$ & Frisch elasiticity \\
\hline$\kappa=0.06$ & coupon & $\varepsilon=6$ & demand elasticity \\
\hline$T=20$ & quarters before default decision & $\alpha=0.33$ & capital share \\
\hline$\zeta=0.5$ & recovery rate & $\theta=0.66$ & Calvo pricing parameter \\
\hline$\psi=0.95$ & probability low surplus state & $\eta=0.65$ & habit parameter \\
\hline$s_{\text {low }}=0.02$ & low state surplus & $\gamma=1$ & indexation parameter \\
\hline $\bar{s}=-0.01$ & surplus before $T$ & $d=2$ & lag in price adjustment \\
\hline & & $\rho=0.8$ & persistence in interest rate rule \\
\hline & & $\psi_{\pi}=1.5$ & inflation parameter in interest rule \\
\hline & & $\psi_{y}=0.1$ & output parameter in interest rule \\
\hline
\end{tabular}




\begin{tabular}{|c|c|c|c|c|}
\hline \multicolumn{5}{|c|}{ Table 2 Sensitivity Analysis } \\
\hline Parameters & $B_{\text {low }}$ & $B_{\text {high }}$ & $\underset{\text { inflation }}{\text { maximum }}$ & $\begin{array}{c}\text { price level } \\
\text { after } \\
\text { inflation }\end{array}$ \\
\hline Benchmark & 0.79 & 1.46 & 23.8 & 5.3 \\
\hline \multicolumn{5}{|c|}{ Lorenzoni-Werning Parameters } \\
\hline$T=10$ & 1.15 & 1.71 & 25.8 & 6.3 \\
\hline$T=30$ & 0.56 & 1.22 & 21.4 & 4.5 \\
\hline$\delta=1 / 40$ & 0.89 & 1.46 & 15.1 & 3.0 \\
\hline$\delta=1 / 10$ & 0.71 & 1.46 & 37.5 & 12.0 \\
\hline $\bar{s}=-0.02$ & 0.58 & 1.28 & 23.2 & 5.1 \\
\hline $\bar{s}=0$ & 1.00 & 1.64 & 23.9 & 5.3 \\
\hline$s_{\text {low }}=0.01$ & 0.28 & 0.63 & 23.2 & 5.1 \\
\hline$s_{\text {low }}=0.03$ & 1.27 & 2.25 & 23.7 & 5.3 \\
\hline$\zeta=0.3$ & 0.46 & 1.46 & 26.4 & 6.1 \\
\hline$\zeta=0.7$ & 1.08 & 1.46 & 21.3 & 4.5 \\
\hline$\psi=0.7$ & 0.98 & 1.46 & 22.0 & 4.7 \\
\hline$\psi=1$ & 0.75 & 1.46 & 24.0 & 5.4 \\
\hline$\beta=0.98$ & 0.61 & 1.17 & 26.7 & 6.7 \\
\hline$\beta=0.995$ & 0.90 & 1.62 & 21.8 & 4.6 \\
\hline \multicolumn{5}{|c|}{ New Keynesian Parameters } \\
\hline$\theta=0.5$ & 0.79 & 1.46 & 23.7 & 5.0 \\
\hline$\theta=0.8$ & 0.79 & 1.46 & 22.9 & 5.5 \\
\hline$\eta=0$ & 0.79 & 1.46 & 22.3 & 4.9 \\
\hline$\eta=0.8$ & 0.79 & 1.46 & 23.8 & 5.3 \\
\hline$\epsilon=4$ & 0.79 & 1.46 & 24.1 & 5.3 \\
\hline$\epsilon=8$ & 0.79 & 1.46 & 23.2 & 5.2 \\
\hline$d=0$ & 0.79 & 1.46 & 19.6 & 4.2 \\
\hline$d=4$ & 0.79 & 1.46 & 29.6 & 7.2 \\
\hline$\sigma=2$ & 0.79 & 1.46 & 22.7 & 5.0 \\
\hline$\sigma=0.5$ & 0.79 & 1.46 & 24.4 & 5.4 \\
\hline$\phi=2$ & 0.79 & 1.46 & 23.6 & 5.3 \\
\hline$\phi=0.5$ & 0.79 & 1.46 & 23.7 & 5.2 \\
\hline$\gamma=0.9$ & 0.79 & 1.46 & 18.0 & 3.2 \\
\hline$\gamma=\eta=d=0$ & 0.79 & 1.46 & 23.0 & 1.7 \\
\hline
\end{tabular}


Figure 1 Multiple Equilibria Lorenzoni-Werning Model

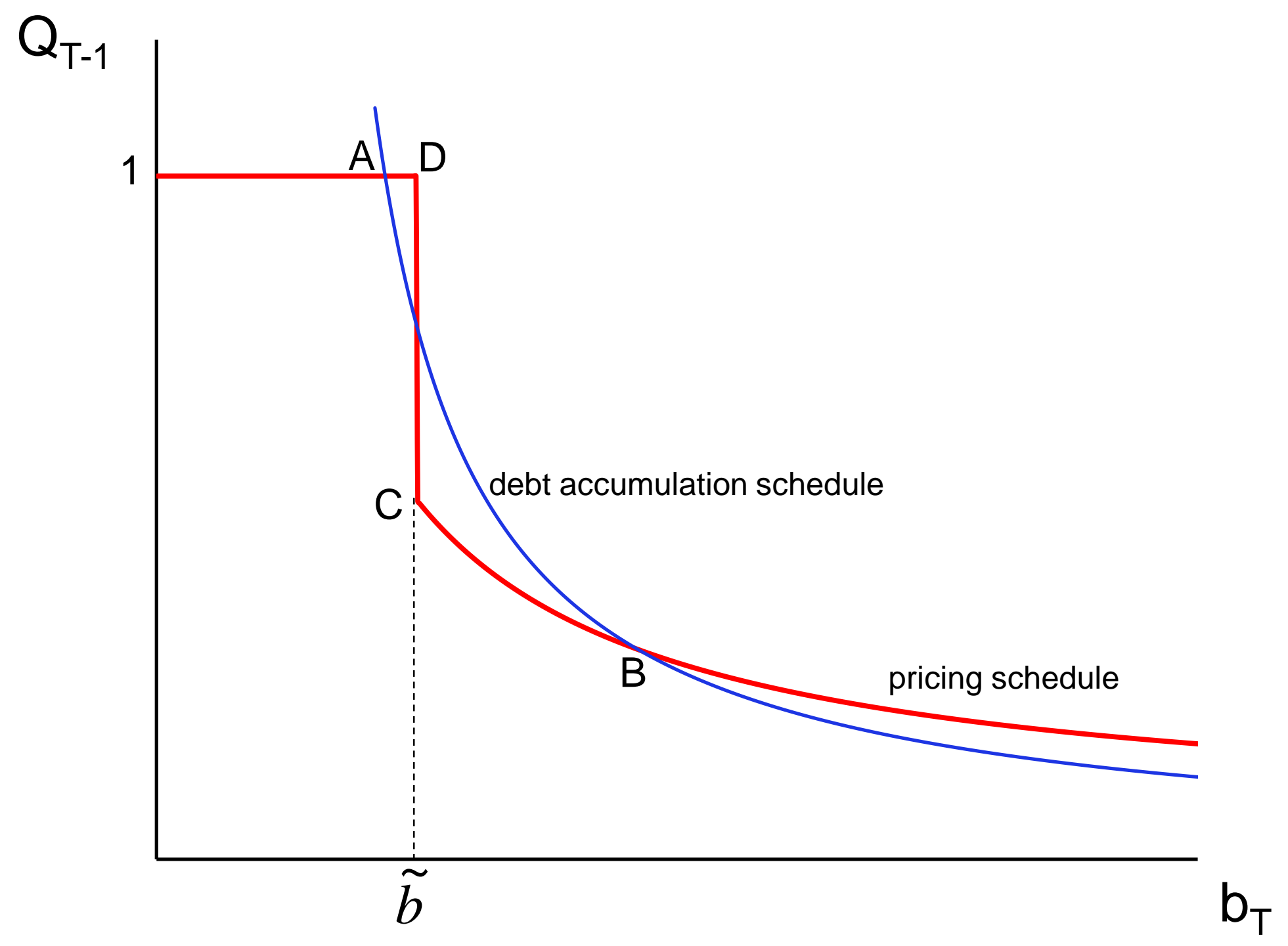




\section{Figure 2 Benchmark NK Model: Inflation Needed to Avoid Default}

Inflation (APR)

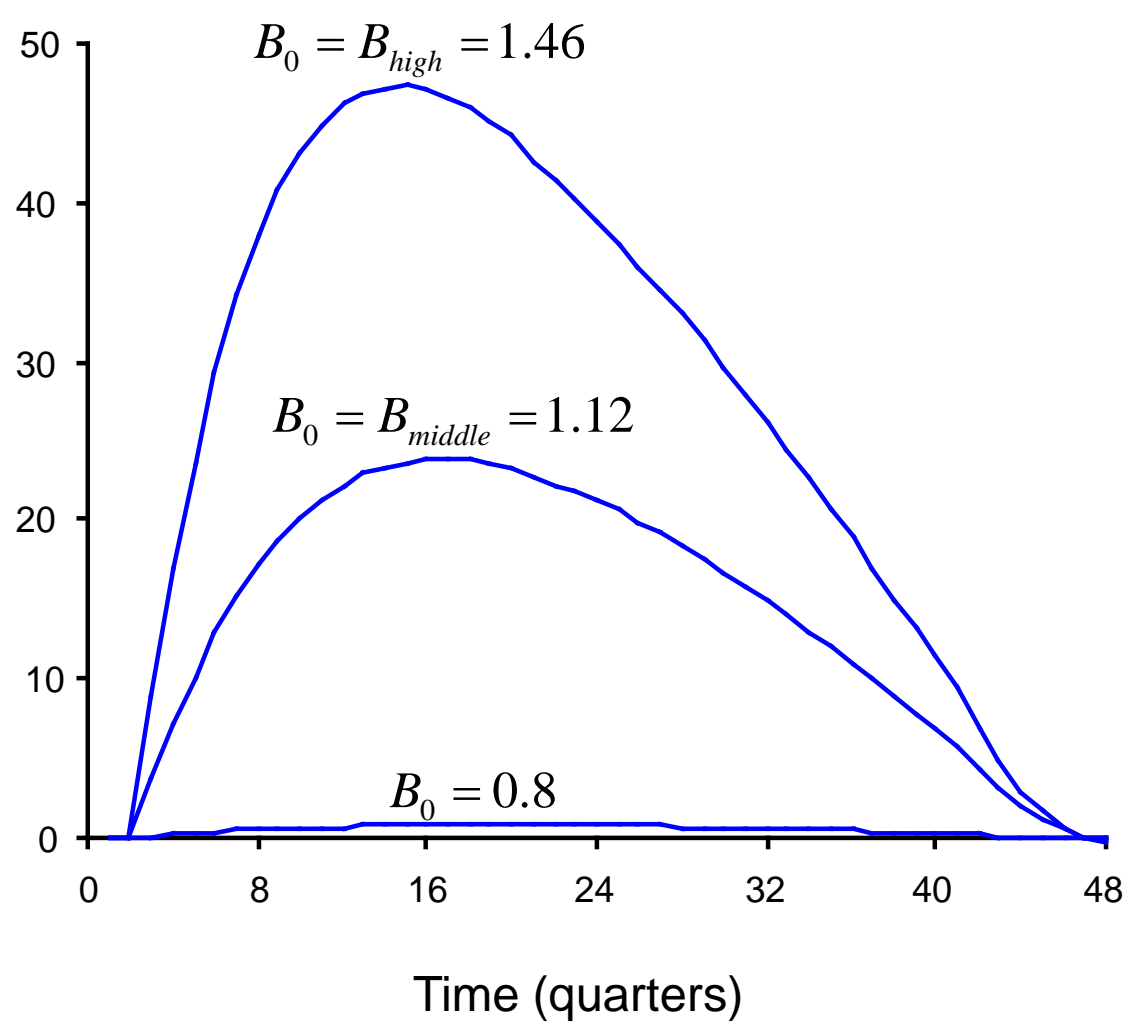

Price Level After Inflation

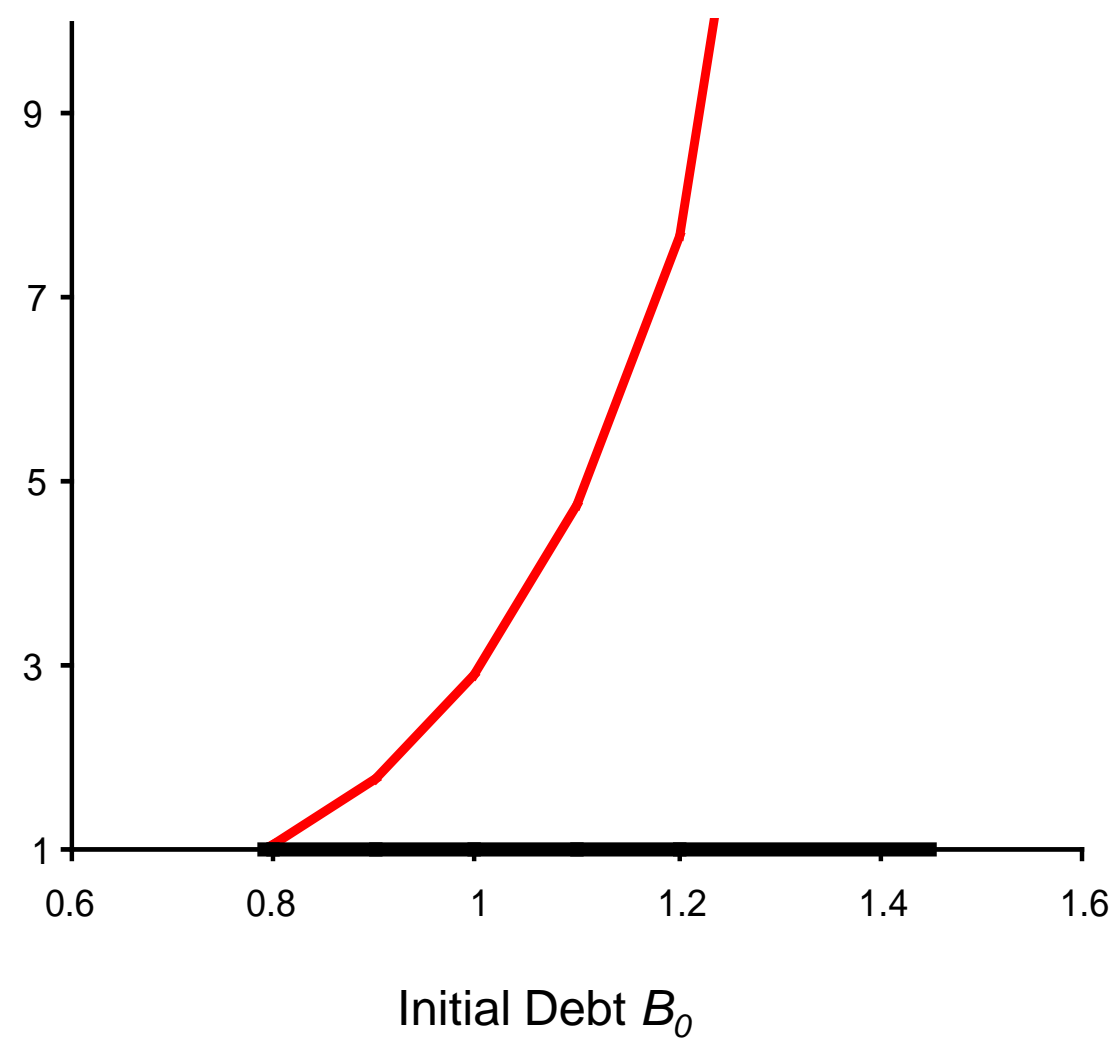


Figure 3 Sensitivity Analysis LW Parameters

$\mathrm{T}, \overline{\mathrm{s}}$ and $\mathrm{s}_{\text {low }}$ for same $\left[\mathrm{B}_{\text {low }}, \mathrm{B}_{\text {high }}\right] \quad$ Inflation when $\mathrm{B}_{0}=\mathrm{B}_{\text {middle }}=1.12$
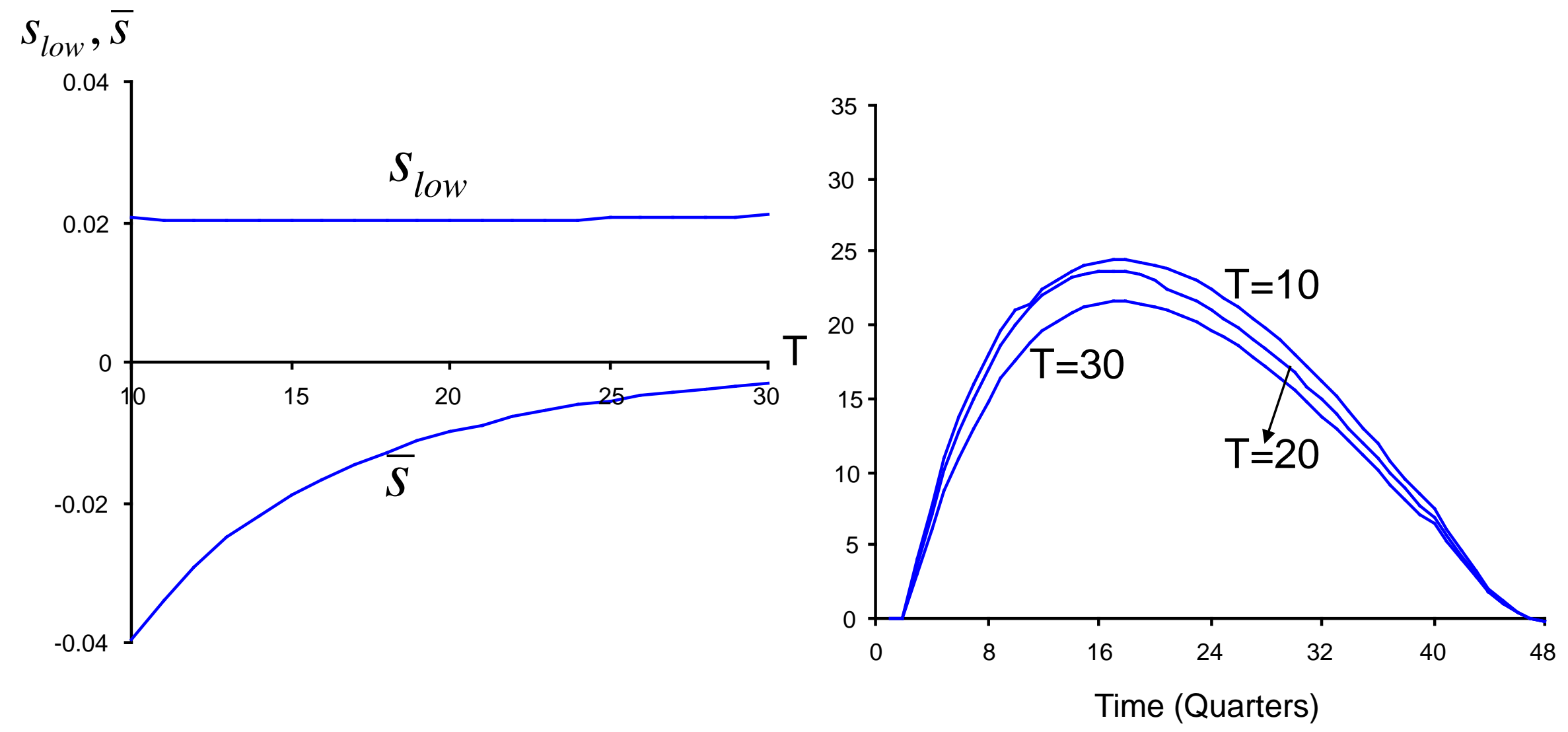


\section{Figure 4 Sensitivity Analysis Optimal Inflation $\left(B_{0} / B_{\text {low }}=1.42\right)$}
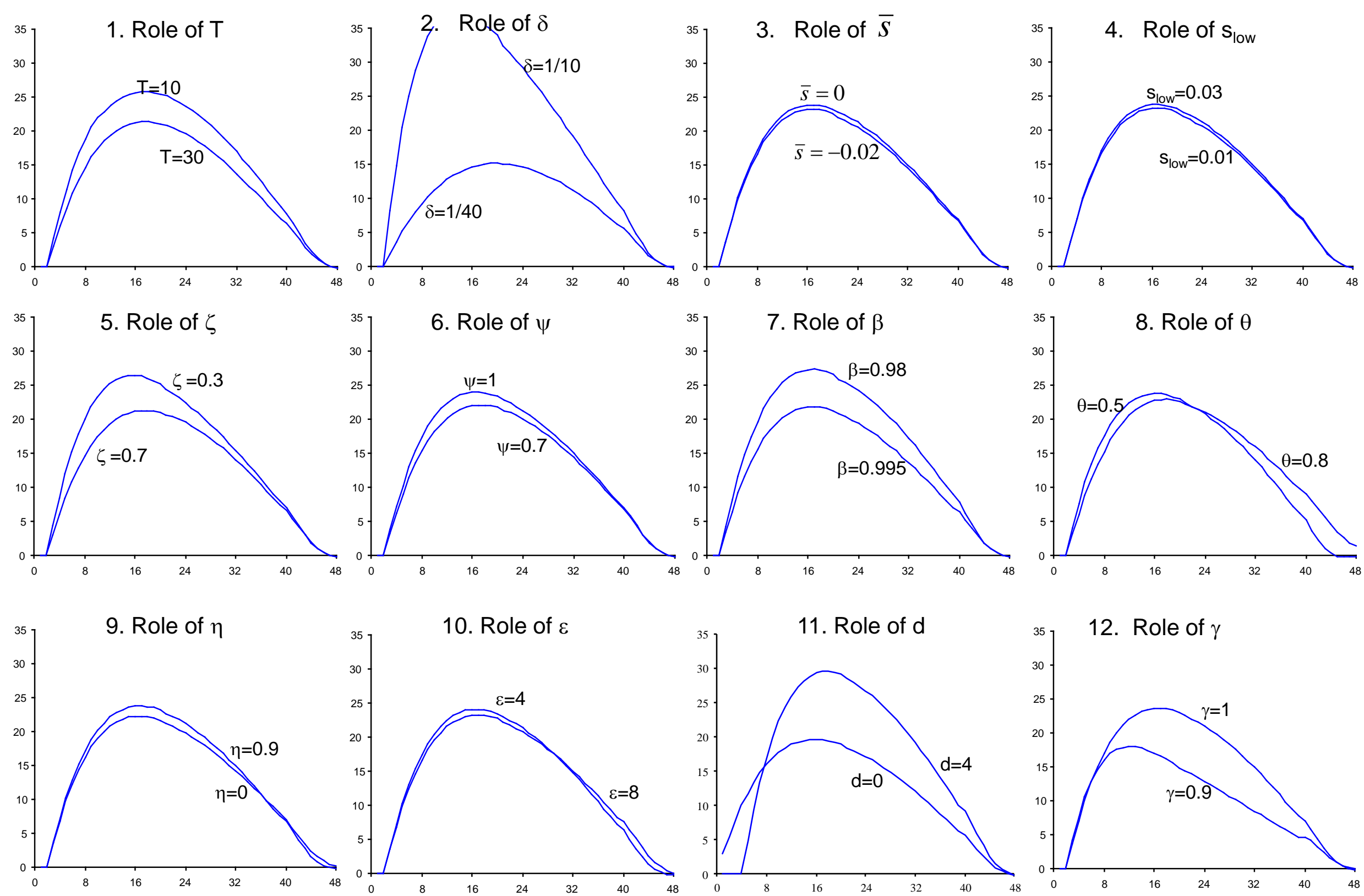